\title{
Rising US Suicides: Achieving Health Equity
}

Seth W. Perry, ${ }^{1,2^{*}}$ Stephen Allison, ${ }^{3}$ Tarun Bastiampillai, ${ }^{3,4}$ Ma-Li Wong, ${ }^{1,2}$ Julio Licinio, ${ }^{1,2,5,6}$ Steven S. Sharfstein, ${ }^{7,8}$ Holly C. Wilcox ${ }^{9,10}$

${ }^{1}$ Department of Psychiatry and Behavioral Sciences, College of Medicine, State University of New York (SUNY) Upstate Medical University, Syracuse, NY USA

${ }^{2}$ Department of Neuroscience \& Physiology, College of Medicine, State University of New York (SUNY) Upstate Medical University, Syracuse, NY USA

${ }^{3}$ Department of Psychiatry, College of Medicine and Public Health, Flinders University, Adelaide, Australia

${ }^{4}$ Mind and Brain Theme, South Australian Health and Medical Research Institute (SAHMRI), Adelaide, Australia

${ }^{5}$ Department of Medicine, College of Medicine, State University of New York (SUNY) Upstate Medical University, Syracuse, NY USA

${ }^{6}$ Department Pharmacology, College of Medicine, State University of New York (SUNY) Upstate Medical University, Syracuse, NY USA

${ }^{7}$ Sheppard Pratt Health System, Baltimore, MD USA

${ }^{8}$ Department of Psychiatry, University of Maryland School of Medicine, Baltimore MD USA

${ }^{9}$ Department of Psychiatry and Behavioral Sciences, Johns Hopkins School of Medicine, Baltimore, MD USA

${ }^{10}$ Department of Mental Health, Johns Hopkins School of Public Health, Baltimore, MD USA

*Correspondence to: perryse" at"upstate.edu

Running title: Suicide \& Health Equity

Key words: suicide; health equity; health disparities; depression; guns; firearms; lethal means; rural; urban; geography; disparity; public health 


\begin{abstract}
Evidence suggests that increased availability of mental health treatment has not significantly reduced depression prevalence and suicide in the US, and that significant personal (i.e., stigma) or practical/logistical barriers to effective mental health care remain. Mental health treatment has increased in the US since the early 1990s with greater use of antidepressant medications, especially SSRIs, however suicide rates continue to climb, with significant gender, ethnic, geographic, socioeconomic, and other health disparities. Depression rates are at best stable, but are increasing in certain subpopulations such as youths ages 12-17. Combating these distressing trends to achieve health equity will require more attention to promising and evidencebased, sustainable, proactive, practical solutions that address the varied causes, demographics, and differential risk factors and mechanisms of suicide deaths. Herein we explore sociodemographic disparities that exist in suicide deaths, with emphasis on two of the largest modifiable targets for suicide prevention: untreated or undertreated depression, and access to the lethal means (firearms) that cause more suicide deaths than all other means combined, and thus pose the greatest threat to individual and public health. Furthermore, we newly define increased or unsafe (i.e. disparate) access to firearms as a suicide health disparity that promotes health inequities. To achieve the greatest results in suicide prevention across all groups, we need 1) more emphasis on policies and universal programs shown to reduce suicidal behaviors, and 2) enhanced focus on the two largest modifiable targets for suicide prevention: depression and firearms.
\end{abstract}




\section{Suicide and Health Equity: A New Framework?}

The National Stakeholder Strategy for Achieving Health Equity defines health equity as the "attainment of the highest level of health for all people. Achieving health equity requires valuing everyone equally with focused and ongoing societal efforts to address avoidable inequalities, historical and contemporary injustices, and the elimination of health and healthcare disparities" (page 9 in [1]). Suicide is linked with determinants of health and healthcare disparities based on age, gender, race/ethnicity, socioeconomic status, geography/urbanization, and sexual minority status, among others. Therefore it is critical that we research and understand these disparities in relation to suicide in order to minimize suicide deaths and achieve health equity.

Moreover, these many disparities in suicide rates, from differences linked to gender, race, socioeconomic status, or any other factors - including disparate access to firearms - should all be viewed and addressed as health equity issues. We suggest that it is through this "health equity" lens by which we may best desensitize and depoliticize these complex and often discomforting and divisive topics, to maximize society's embrace of shared goals and meaningful progress in suicide prevention at all levels, from legislative action to the dissemination and implementation of universal programs aimed at the general public.

\section{Suicide and Health Disparities}

The rising US suicide rate since 1999 is a significant public health concern, with marked and often increasing disparities in suicide rates observed between groups. CDC data reveal that the overall age-adjusted US suicide rate increased by 33\% from 1999 - 2017 (10.5 to 14.0 per 100,000 standard population) [2], with notable disparities based on gender, age, race/ethnicity, income, education, and geography (urbanization), among others [2,3] (and see below). This has led the 
Centers for Disease Control and Prevention (CDC) to call for acceleration of "efforts to eliminate health disparities [in suicide] with a focus on surveillance, analysis, and reporting of disparities and the identification and application of evidence-based strategies to achieve health equity" [4].

Gender: From 1999-2017, the age-adjusted suicide rate for females (all ages and races/ethnicities) increased from 4.0 to 6.1 per 100,000 population (a 53\% increase), whereas the age-adjusted male suicide rate increased from 17.8 to 22.4 per 100,000 (a $26 \%$ increase) [5]. Therefore while males experienced a lesser rise in suicide rates over this time period, their suicide rates were 4.5 times those of females in 1999, and 3.7 times those of females in 2017. There is a recent narrowing of the gender gap in suicide.

Age: In males, suicide rates generally increase with age, and are highest in the $\geq 71$ years old age bracket, followed by 51-70, 36-50, 25-35, 19-24, 13-18, and 6-12 years old (y.o.) brackets (Figure 1A). In recent years the differences in suicide rates between younger and older males have narrowed, as younger male suicides have increased more sharply since about 2009. In the $\geq 71$ y.o. group, suicide rates declined slightly from 1999-2017 (0.95x), although have increased steadily from a low point in 2009. In all other male age brackets suicide rates have increased since 1999, and typically most sharply since about 2005-2008, with 6-12 y.o. males seeing the largest increase from 1999-2017 (1.86x), followed by 13-18 and 51-70 y.o. males (both 1.4x). In females, 19992017 suicide rates have been highest in 36-50 year olds, followed closely by 51-70 y.o., then 25 35, 19-24, 71-85+, 13-18, and 6-12 y.o. (Figure 1A). From 1999-2017, female suicide rates rose in all age groups except 71-85+ which remained steady (1.02x). The greatest fold-increases were observed in 6-12 y.o. (3.11x), followed by 13-18 (2.34x), 19-24 (1.78x), 51-70 (1.62x), 25-35 $(1.51 \mathrm{x})$, and $36-50(1.44 \mathrm{x})$. Thus young females $\leq 24$ y.o. have the most rapidly rising suicide rates since 1999, with suicide rates for 13-18 and 19-24 y.o. females now equaling or surpassing, 
respectively, rates for 71-85+ females (Figure 1A). As with males, the sharpest rise for most

female age brackets has generally occurred since $\sim 2005-2008$.
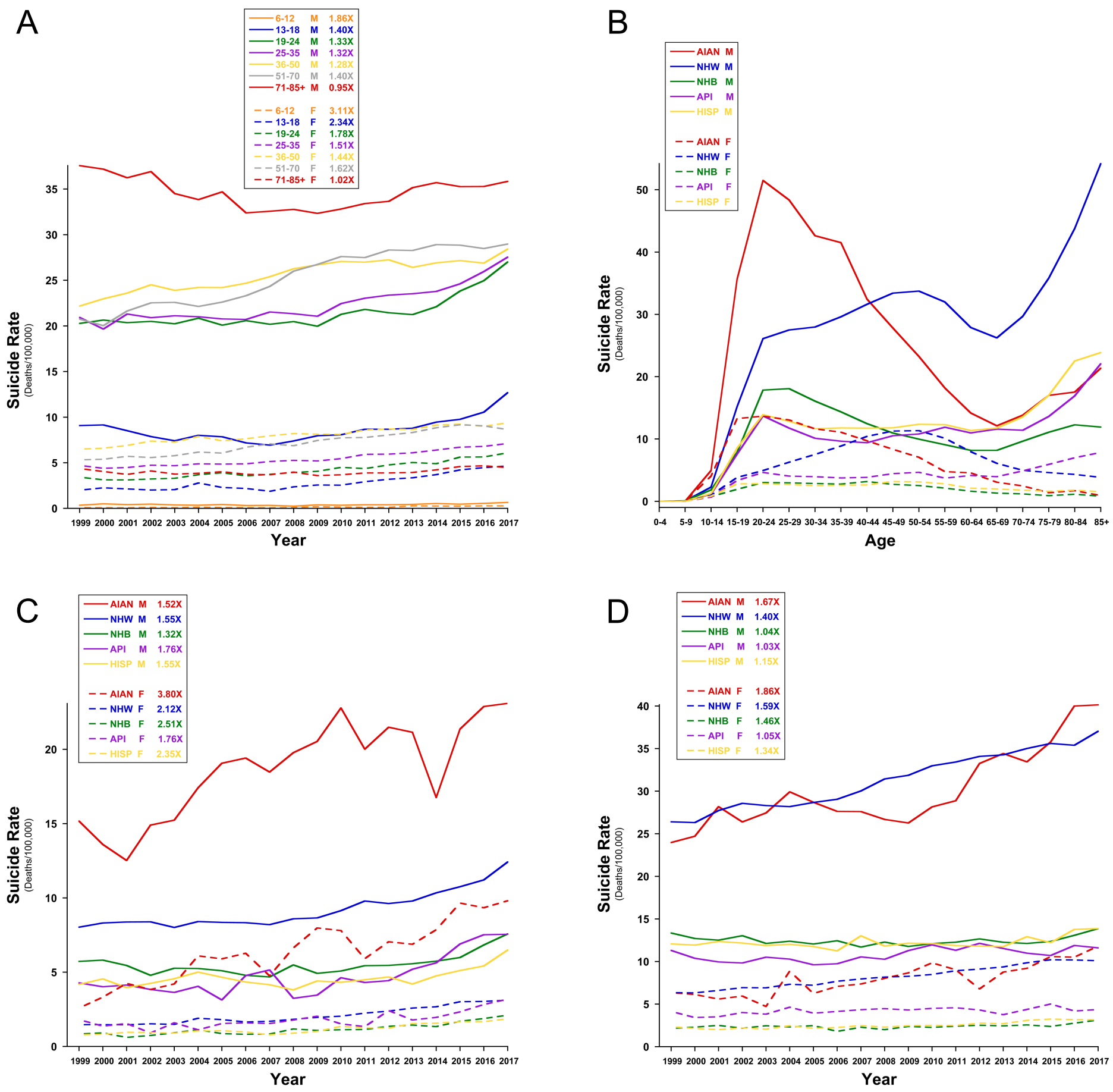

Figure 1: Suicide Disparities by Age, Race/Ethnicity, and Gender. Suicide deaths per 100,000 are shown by A) Age bracket and year, B) Age bracket and race/ethnicity over the lifespan using cumulative 1999-2017 data, C) 24 y.o. and under by race/ethnicity and year, and D) Over 24 y.o. by race/ethnicity and year. All rates are stratified by age, and therefore are crude rates, for males (M) and females (F) separately. All data is from WISQARS Fatal Injury Reports [5]. 
Race/ethnicity stratification reveals hidden patterns: Looking at suicide rates across the lifespan as above, in the general population suicide rates peak in mid-life for women, and late-life for men. (Using slightly different age brackets yields similar results for both sexes [2].) However, these numbers are skewed toward those of the non-Hispanic white (NHW) population, which comprises the greatest numbers of individuals and suicide deaths. When the numbers are further stratified for race/ethnicity, different patterns are revealed that may help inform targeted outreach for prevention approaches.

Suicide deaths for NHW females indeed increase steadily to a mid-life peak at about ages 45-54, followed by tapering into older age (Figure 1B). However in Hispanic (HISP) and nonHispanic black (NHB) females, rates reach an initial peak at ages 15-19 and 20-24 respectively, followed by a fairly steady plateau until about age 50 , then a steady decline thereafter. Asian/Pacific Islander (API) females also show this early peak-then-plateau pattern, except unlike HISP and NHB (and NHW) females whose suicide rates decline after middle age, API suicide rates then sharply increase from about age 50-55 onward (Figure 1B). This makes API females the only female racial/ethnic group with increased suicide rates beyond age 50, a pattern more commonly seen in older males (next paragraph). Finally, suicide rates in American Indian/Alaska Native (AIAN) females sharply increase to peak at 15-19 y.o., followed by a gradual but steady decline into older adulthood. Together these data indicate that among females, AIANs have the highest suicide rates until about age 40; NHW females have the highest rates from ages 40-70; and API females have the highest rates after age 70. Identification of the factors that may make some racial/ethnic groups more or less vulnerable to suicide during certain life stages (ages) are worth further exploration, to best inform suicide prevention efforts.

In males, suicide rates across the lifespan amongst different racial/ethnic groups are 
generally more similar to one another (Figure 1B). Suicide rates in all male groups increase sharply to age 20-24, with AIAN male suicide rates far surpassing those of all other groups at this age bracket. From age 20-24 onward, AIAN and NHB male rates decline steadily to age 65, then increase thereafter. HISP and API male rates are fairly steady until age 65 or 70 respectively, then increase after. NHW male suicide rates rise from age 20-24 to a second peak at age 50-54, then decline to ages $65-69$, then increase the most sharply thereafter. Thus in males, all racial/ethnic groups experience sharply increasing suicide rates after ages 65-70, whereas in same-age females suicide rates are on the decline across all groups except API (which, like males, also increase in late age). Comparing across all male racial/ethnic groups, AIAN males have the highest suicide rates until age 40-44, whereas NHW males have the highest rates after age 40-44 (Figure 1B). Finally, while female suicide rates are on average lower than male suicide rates, the suicide rates of some female populations may surpass those of some male populations at several points in the lifespan, particularly for younger AIAN females and middle-aged NHW females (Figure 1B).

Youth versus adult suicides: For both males and females, the sharp rise in suicide rates since $\sim 2007$ is particularly pronounced in youth and young adults ( $\leq 24$ y.o.) and especially young females (Figure 1C), compared to older adults ( $\geq 25$ y.o.) (Figure 1D), a distressing trend that has recently been highlighted elsewhere [6]. All $\leq 24$ y.o. male and female populations experienced a rise in suicide rates between 1999 and 2017, ranging from 1.32 (NHB) to 1.76 (API) fold increases for males, and 1.76 (API) to 3.80 (AIAN) fold increases for females (Figure 1C). Differences in suicide rates across $\leq 24$ y.o. female populations have remained fairly constant, with the exception of $\leq 24$ y.o. AIAN females whose rates have increased disproportionately to all other racial/ethnic groups, and who now have higher suicide rates than all $\leq 24$ y.o. male populations except NHW and AIAN. Likewise, since 1999, there are increasing disparities in the suicide rates of $\leq 24$ y.o. 
NHW and especially AIAN males compared to other same-age male populations (Figure 1C)

In contrast, among $\geq 24$ y.o. males, AIAN experienced the greatest rise in suicide rates between 1999-2017 (1.67x), followed by NHW males (1.40x) and HISP males (1.15x), with sameage NHB (1.04x) and API (1.03x) male populations having relatively stable suicide rates over the same time period (Figure 1D). As a result, suicide rate disparities between $\geq 24$ y.o. NHW and AIAN and other same-age male populations have grown in recent years (Figure 1D). Among $\geq$ 24 y.o. females, AIAN suicide rates increased the most from 1999-2017 (1.86x), followed by NHW (1.59x), NHB (1.46x), HISP (1.34x), and API (1.05x) females respectively. As with $\geq 24$ y.o. males, NHW and AIAN female suicide rates have grown disproportionately to other $\geq 24$ y.o. female racial/ethnic groups. For both age groups and all racial/ethnic groups, females had equal or most often greater rises in suicide rates versus their male counterparts.

Together these data highlight a number of disparities in suicide rates across age, sex, and racial/ethnic groups. Better understanding of the factors driving these disparities is needed to achieve more effective suicide prevention efforts.

Sexual or gender minority status: Data suggests that those having a minority sexual orientation or gender identity are at increased risk for suicide across ages and race/ethnicities [716], and in other groups at high risk for suicide such as veterans [17, 18], but at present the numbers of individuals in these groups who die by suicide are difficult to track because sexual orientation and gender identity information is typically not collected at time-of-death [19]. These are critical areas for further research, improved data collection, and targeted suicide prevention efforts.

Income and education: US suicide rates also reflect significant disparities based on socioeconomic factors such as income or education, with higher rates typically associated with lower socioeconomic status. Correlations between income, education, and other socioeconomic 
factors and suicide rates will be discussed in later sections. These and other health, healthcare (including access-to-care), and environmental disparities and inequalities that are closely linked to suicide and determinant to health and health equity will be highlighted throughout this paper.

Veterans: America's veteran population is also at increased risk for suicide. From 2005 to 2017, age- and sex-adjusted suicide rates increased $22 \%$ in the general population (from 14.7 to 18.0 per 100000), but increased by $50 \%$ amongst veterans over the same time period (from 18.5 to 27.7 per 100,000 ) [20]. In 2017 , veterans' suicide rate was $1.5 \mathrm{x}$ the rate of non-veteran adults (using age- and sex-adjusted rates) [20]. The U.S. Department of Veterans Affairs (VA) and U.S. Department of Defense (DoD) have recently updated and released comprehensive guidelines for assessing and managing veteran and military populations at risk for suicide [21, 22]. These guidelines and materials are notable for their common-sense, empowering, and collaborative language around the issue of lethal means risk assessment and reduction in at-risk veterans, including but not limited to firearms, and as such may provide a useful model for broader national conversations around these issues as they might be applied to suicide prevention in the civilian population. That a substantial number of veterans may not utilize or be eligible for VA care only highlights the urgency and need to translate programs of this nature to the broader US population [23]. Highlighting this urgency, reports indicate that 70 percent of veterans who died by suicide were not engaged with VA care or services in the two years prior to their death [24-26]. Efforts such as the recent (March 5, 2019) President's Roadmap to Empower Veterans and End a National Tragedy of Suicide (PREVENTS) executive order [27], and other similar state and local initiatives $[20,26]$ intended to increase resources and efforts devoted to reducing suicides of veterans and other service members, especially outside the VA network, are important steps in the right direction that may also have useful translations to the broader public. 
Geography (urbanization/rurality): Within the US, suicide rates are consistently highest in rural areas, followed by medium-sized cities, and lowest in large cities (Figure 2A) [3, 28-31]. This is true for both men and women and all racial/ethnic groups, with the exception of NHB (Figure 2B) (and see below) [3]. In other words, increased suicide rates track closely with increasing rurality (decreasing urbanization). From 2001-2015, suicide rates increased in all urbanization categories, but increased more rapidly in medium/small metro and non-metro/rural areas [3, 29], resulting in growing disparities in suicide rates between these regions (Figure 2A). Strikingly, all racial/ethnic groups, all age groups, and both men and women, experience their highest suicide rates in rural areas and lowest suicide rates in large metro areas, with the exception of NHB who experience slightly lower suicide rates in the most rural versus the most urban areas (Figure 2B) [3]. Moreover, for all racial/ethnic groups, and both men and women, the rise in suicide rates from 1999 to 2015 was greatest in more rural (less urban) areas compared to less rural (more urban) areas (Figure 2C). For example, NHB and HISP had similar 1999 and 2015 suicide rates in large metro areas $(\sim 1 \mathrm{x})$, whereas they had $\sim 1.1 \mathrm{x}$ increased suicide rates in rural areas between 1999 and 2015. Similarly, between 1999 and 2015, AIAN had about 1.3x increased suicide rates in large metro areas, $\sim 1.6 \mathrm{x}$ rates in medium/small metro areas, and $\sim 1.43 \mathrm{x}$ rates in non-metro/rural areas (Figure 2C). 

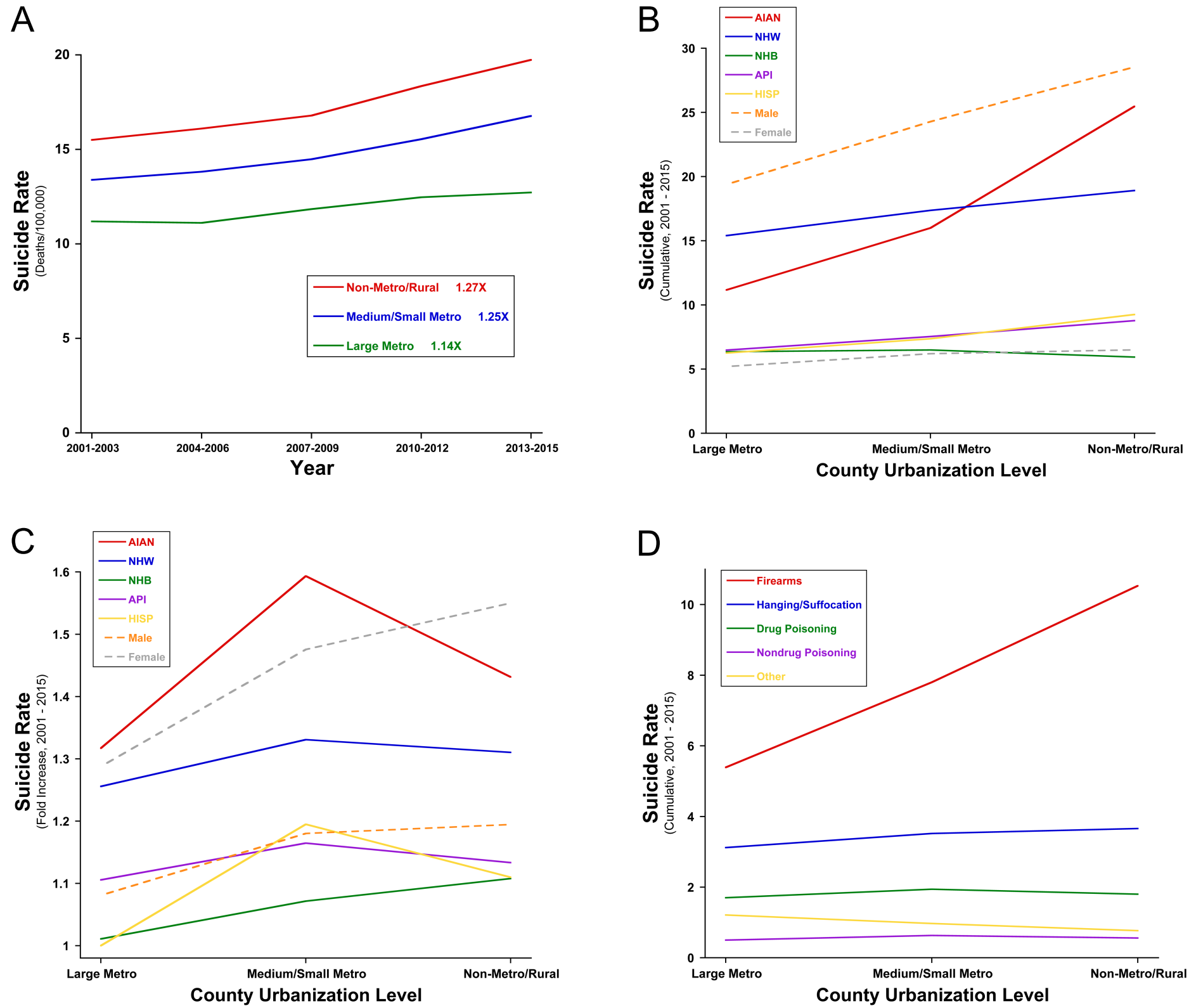

Figure 2: Suicide Disparities by Urbanization, Race/Ethnicity, Gender, and Mechanism of Death. Suicide deaths per 100,000 by A) Year and relative county urbanization, B) County urbanization, race/ ethnicity, and gender (aggregate 2001-2015), C) Fold-increase in suicide 2001-2015, by race/ethnicity and gender, and D) County urbanization and mechanism of death. All age-adjusted, 2000 US population. 2006 county urbanization classification [32]. All plotted data is derived from the Tables in Ivey-Stephenson (2017) [3].

These trends have continued through 2017, the most recent data available [2]. Table 1 shows that in 1999, overall suicide rates were 10.04 (per 100,000) in metro areas, and 12.60 in non-metro areas, a 1.255-fold difference. In 2017, overall rates were 13.20 in metro and 19.17 in non-metro areas, a 1.452-fold difference. Furthermore, from 1999 to 2017, the overall suicide rate 
increased $1.315 \mathrm{x}$ in metro areas $(10.04$ to $13.20 / 100,000)$, and $1.522 \mathrm{x}$ in non-metro areas $(12.60$ to $19.17 / 100,000)$. Together these data highlight growing disparities in suicide rates by relative degree of urbanization, that are consistent across sex and race/ethnicity.

\begin{tabular}{lcc|cc} 
& $\mathbf{1 9 9 9}$ & $\mathbf{2 0 1 7}$ & Raw Increase & Fold Increase \\
Metro & 10.04 & 13.20 & 3.16 & 1.315 \\
Non-Metro & 12.60 & 19.17 & 6.57 & 1.522 \\
\cline { 1 - 2 } Raw Increase & 2.56 & 5.97 & & \\
Fold Increase & 1.255 & 1.452 & &
\end{tabular}

Table 1: All Suicides, 1999 versus 2017, by County Urbanization

All data is age-adjusted deaths per 100000 (2000 US population) [5], except Fold Increase. 2006 county urbanization classification [32].

Suicide means versus urbanization/rurality: Relative urbanization/rurality also creates a means disparity, with regard to the mechanism of death by which suicides occur. Cumulative suicide rates 2001-2015 demonstrate that suicide means were relatively consistent across the different urbanization geographies, with one exception: firearms. The rate of firearm suicides approximately doubled, in very linear fashion, as relative urbanization decreased (Figure 2D). Moreover, using cumulative suicide data from 1999-2017 [5], both sexes, and all racial/ethnic and age groups examined, had higher gun suicide rates and higher percentages of suicides by gun in non-metro versus metro areas (Table 2). The only exceptions were NHB females, who had an essentially equivalent gun suicide rate in metro versus non-metro areas $(0.57$ versus 0.56 , respectively), and AIAN females, who had an essentially equivalent percentage of suicides by gun in metro versus non-metro areas (23.9\% versus $23.7 \%$, respectively) (Table 2$)$. The implications of these observations for health equity are discussed in greater detail below. 


\section{METRO}

Gun Suicides Rate All Suicides Rate \% Suicides by Gun Gun Suicides Rate All Suicides Rate

Population

6-12 yo M

13-18 yo $\mathrm{M}$

19-24 yo $\mathrm{M}$

25-35 yo $\mathrm{M}$

36-50 yo $\mathrm{M}$

51-70 yo $\mathrm{M}$

71-85+ yo $\mathrm{M}$

$\begin{array}{cc}0.09 & 0.4 \\ 3.73 & 7.88 \\ 10.22 & 20.21 \\ 9.79 & 20.84 \\ 11.24 & 24.1 \\ 14.7 & 24.76 \\ 25.31 & 32.69\end{array}$

AIAN M

8.16

12.53

NHW M

5.55

NHB M

API M

HISP M

2.42

4.07

All Males

10.04

0.01

6-12 yo $\mathrm{F}$

13-18 yo $\mathrm{F}$

19-24 yo $\mathrm{F}$

25-35 yo $\mathrm{F}$

36-50 yo $\mathrm{F}$

51-70 yo $\mathrm{F}$

71-85+ yo $\mathrm{F}$

AIAN F

NHW F

NHB F

API F

HISP F

All Females
0.6

1.18

1.57

2.22

2.22

1.3

1.40

1.90

0.57

0.33

0.41

1.41
18.80

22.38

9.96

8.62

9.65

18.31

0.15

2.69

4.14

5.26

7.71

7.31

4.18

5.86

6.13

1.99

3.38

2.07

4.82
22.5

47.3

50.6

47.0

46.6

59.4

77.4

43.4

56.0

55.7

28.1

42.2

54.8

6.7

22.3

28.5

29.8

28.8

30.4

31.1

23.9

31.0

28.6

9.8

19.8

29.3
0.19

7.28

16.98

17.58

19.62

21.96

37.19

16.29

18.12

5.83

4.10

6.99

16.36

0.03

1.08

1.91

2.82

4.02

3.56

1.73

2.20

2.72

0.56

0.80

0.71

2.40
NON METRO

All Suicides Rate \% Suicides by Gun 


\section{Health disparities in antidepressant use, suicide, and depression}

Depression is the leading psychiatric risk factor for suicide, with $\sim 60 \%$ of suicides occurring among those with mood disorders [33]. Yet the majority of individuals who suffer from depression do not go on to make an attempt or die by suicide: roughly $2 \%$ of those with a history of outpatient depression treatment will die by suicide, versus $4 \%$ of those with a history of inpatient depression treatment [33]. Approximately $7 \%$ of men and $1 \%$ of women with lifetime histories of depression will die by suicide [33]. Unfortunately, many of those with depression are not treated, are undertreated, or are unsuccessfully treated, likely contributing to these statistics.

The introduction of SSRI antidepressants in 1988 was associated with reduced suicide rates [34], but greatly expanded antidepressant use in the US since 1999 has not prevented the more recent rise in US suicide rate. The CDC reports that from 1999 to 2014, antidepressant use increased from $7.7 \%$ to $12.7 \%$ of the US population (a $65 \%$ increase) [35], which is very high by international standards. Yet, the overall age-adjusted US suicide rate still increased by $24 \%$ over the same period (10.48 to $12.96 / 100000)$ [5]. NHW were more likely to use antidepressant medication than any other racial/ethnic groups [35], but still had higher suicide rates than most groups except AIAN (Figure 1). While 16.5\% of the NHW population used antidepressants, NHB (5.6\%), HISP (5.0\%), and API (3.3\%) all had lower antidepressant use [35]. Thus despite NHW being 3 to 5 times more likely to use antidepressants than these other racial/ethnic groups, they had 2 to 3 times the suicide rate. AIAN antidepressant use is likely to be under $2 \%$ [36], meaning that the two groups with the highest suicide rates - the AIAN and NHW population groups - had both the lowest and highest antidepressant usage, respectively.

Are US depression rates (or disparities) rising along with suicides and antidepressant use? That question has been more difficult to answer definitively. Using data from the National Survey 
on Drug Use and Health (NSDUH) (N = 607,520 US individuals aged 12 and older), this report [37] found that: 1) the total prevalence of past-year depression (all racial/ethnic groups and ages, unstratified) increased significantly from 2005-2015, 2) only NHW reported a significant increase in depression over this time period. The "all other races" group had significantly increased depression over this time period only in unadjusted analysis, whereas depression did not increase in NHB or HISP [37]. The authors further highlighted that although the 2005-2015 trend lines for depression were not significantly different by racial/ethnic group, the trend line for NHW was consistently higher than all other groups [37]. In other words, these depression data bear similarities to the stratified suicide rates plotted in Figure 1D (herein), as one might expect if depression prevalence were correlated with suicide rate.

Depression prevalence and suicide attempts are higher in women than men, and in lower income groups versus higher income groups [38]. Suicide rates (i.e. completed suicides), in contrast, are significantly higher in men than women, suggesting that the suicide rate is not predictable by depression rate alone (independent of gender), and that other factors come into play. Factors likely contributing to this paradox include whether men may have higher prevalence of untreated or undiagnosed depression, and/or greater stigma or increased resistance to seeking care. Another likely factor is that men use guns for suicide at much higher rates than women (Table 2). Men's disproportionate choice of far more deadly means - roughly $85-90 \%$ of suicide attempts by firearm are fatal $[39,40]$, compared to $3 \%$ fatality from drug overdose suicide attempts [40] likely contributes significantly to their higher suicide rates despite having many fewer suicide attempts than women.

Antidepressant use is also higher in women than men [35], and NHW's reported rates of antidepressant use [35] exceeded their depression prevalence as found in NSDUH reports [37], 
whereas antidepressant use was less than or equal to depression prevalence for NHB, HISP, and API. This may reflect an increased "access gap" for NHB, HISP, and API among those surveyed, although it also seems probable that those with the most severe "access gaps" across all groups are least likely to be reached by surveys.

In total, suicide rates and disparities are increasing, antidepressant use is increasing and highest in NHW, and depression may be increasing (or at best is stable but not decreasing). The evidence also suggests that simply a (further) increased rate of antidepressant use, at the population level, is not likely to be effective at significantly reducing the overall suicide rate (although better and more individually-tailored pharmacologic or psychosocial treatments may be, discussed below). Moreover, the rising and disparate suicide rates may not be due simply to higher or differing rates of depression or other diagnosed mental illness between the groups [41]. Issues of access to care and identification of potentially existing but as-yet-unknown mental health conditions, or other life factors that may be substantially distressing and debilitating without meeting clinical criteria for diagnosable mental illnesses, as well as access to disproportionately lethal means, are all considerations that clearly we must do better at among all groups, and perhaps particularly among underserved and marginalized populations. These imperatives notwithstanding, this available data makes clear that in order to most effectively minimize suicides and maximize public health in the US, we will need to employ multi-pronged preventative measures that reach well beyond only those individuals with pre-identified mental health issues.

\section{Suicide prevention in the antidepressant era}

What can be done to reduce these distressing trends, to improve individual and public health and achieve health equity? We suggest that increased research and understanding of inter- 
and intra-populational suicide factors are needed in at least three key areas: 1) The underlying contributory (e.g. social, economic, cultural, medical, or other) factors that are driving these trends, 2) Which predisposing factors interact to increase risk and which protective factors reduce risk in the context of predisposing factors - e.g. social, cultural, or biological, and 3) What methods and strategies are most effective for suicide prevention? Some progress has been made in all of these areas, but clearly much work remains to be done. In this burgeoning era of personalized medicine, a key goal of these efforts should be more effective, individually and community tailored treatment and intervention approaches for preventing suicide deaths, which we believe can only arise from a more complete and integrated understanding of all the factors above. Excellent reviews of the multi-factorial nature of suicide, its causes, and limitations of the body of literature, have also recently been published in the literature [42] and media [43]. Inherent in finding the answers to these questions is a pressing need for substantially increased funding for both suicide prevention research, and suicide prevention efforts.

Driving Forces: In two papers that generated vigorous discussion and mild controversy (expertly discussed in [44]), Anne Case and Angus Deaton, the 2015 Nobel Laureate for Economics, highlighted the unprecedented rise in midlife mortality among socioeconomically disadvantaged middle-aged NHW Americans [45, 46]. These researchers linked rising midlife mortality to a decline in the economic prospects for the NHW working class during an era of rising income inequality in the USA. Widening income inequality was associated with greater health inequality $[45,46]$, as Americans' socioeconomic status is directly correlated with longer, happier, and healthier lives [47]. Further, the authors linked increased mortality and disproportionately rising suicide rates among NHW to socioeconomic and educational disparities, chronic ailments, and generational (birth-year) cohort effects, with more recent generations faring worse in most or 
all categories examined $[45,46]$. From this, they postulate a "cumulative disadvantage from one birth cohort to the next, in the labor market, in marriage and child outcomes, and in health" [46] as driving increased NHW mortality and suicides (i.e. drug/alcohol related deaths and suicides, or "deaths of despair"). A detailed and more recent analysis found associations between higher suicide rates and higher: deprivation (especially in rural areas); social fragmentation; percent uninsured; and percent veterans [48]. Lower suicide rates, in contrast, were associated with higher social capital [48]. Others have presented similar or complementary data and analyses, with similar conclusions and useful discussions $[49,50]$.

Following from their examination of the NSDUH data which showed that compared to other racial/ethnic groups only NHW experienced a significant increase in depression from 20052015, Weinberger et al. also presented a thoughtful, comprehensive, and comparative epidemiological discussion of depression risk factors, demographics, and driving forces amongst the racial/ethnic groups surveyed [37] (which closely interrelates with the expert discussion in [44]). (Nonetheless, and particularly in populations or individuals with significant disparities, we cannot discount the possibility that much depression may go undiagnosed, either because it may differ from a classic clinically-diagnosable depression, such as demoralization or disenfranchisement, or it may simply go unsurveyed.) Of interest in the context of these analyses, one of the most consistently identified risk factors for depression and suicide, broadly across races/ethnicities and nationalities in the US and worldwide, is one's income bracket $[37,45,46$, 51], or perhaps more specifically, one's income "rank" or socioeconomic status (often also correlated with lower educational status) [52-56].

Many AIAN populations may share similar risk factors and disparities - very high poverty rates, low economic prospects, education gaps, frequent rural living, as well as lower access to 
mental health care and high gun ownership rates - and these same factors may be key contributors to the rise in suicides amongst this population over the same time period [57]. Others have also noted the disparate rise in premature mortality among NHW and AIAN, with these increases being "mainly attributable to accidental deaths (primarily drug poisonings), chronic liver disease and cirrhosis, and suicide," in contrast to declining premature mortality for HISP, NHB, and API [58]. Across all racial/ethnic groups, AIAN have both the fastest rising and highest premature mortality [58], and the highest suicide rates, making them a particularly vulnerable population.

At the same time, AIAN suicide rates are not uniform across all AIAN populations. While AIANs overall, and therefore many AIAN subgroups, have higher suicide rates than NHW, many other AIAN populations have lower suicide rates than NHW living in the same region [57]. AIAN $\geq 45$ y.o. or $\geq 65$ y.o. have lower suicide rates than same-aged NHW in much of the USA, and AIAN of all ages in the Eastern USA also tend to have lower suicide rates than Eastern NHW [57]. Understanding the driving forces for these vastly differing suicide rates among AIAN subpopulations, and compared to other racial/ethnic groups, will help develop more effective suicide prevention measures and reduce health inequities in these vulnerable populations.

Despite favorable public health gains in some areas and lower suicide rates versus other groups (Figure 1), NHB have the second highest premature mortality after AIAN, seemingly high rates of adult depression relative to other groups [51] often coupled with significant gaps in access to mental health care, and have seen a recent sharp rise (and reversal of trend) in premature mortality across all age groups in those with less than a high school education (similar to NHW in this regard, in recent years) (Figure 1.2 in [46]), all of which remain important public health considerations that require remedy.

Particularly against the backdrop of polarizing current events, the topics of race, ethnicity, 
class, culture, and historical or contemporary discrimination, oppression, or trauma, can be especially sensitive issues that are extraordinarily difficult to adequately and comprehensively address, even in the context of health disparities and when authors have only humanitarian intentions. In this light, the controversy and discussion that emerged from the Case and Deaton papers have been very thoroughly, thoughtfully, and expertly covered in great detail by others, and we refer readers there for those discussions [44] (and see additional relevant discussion in [37]). Perhaps a fair (albeit over-simplified) consensus that emerged from those discussions might be summarized as follows: While it is reasonable and in fact desirable to devote attention to groups that, for one reason or another, may be more impacted by depression or suicide (or other illness) in order to inform and guide public health efforts aimed at reducing suicide and other consequences of depression, we must also keep an eye on the larger goal, which is broad-scale maximization of individual and public health by minimizing depression and suicide rates and maximizing quality of life for all groups, regardless of race, ethnicity, class, gender, or any other stratifying variable. In other words, we must strive for health equity.

Reducing the Access Gap: If there is a single hard truth amongst this data, it is that we cannot help those we don't reach. And it is indeed likely that adequate mental health treatment is not reaching many of the most vulnerable subgroups and individuals across all races/ethnicities, or may not be sufficiently culturally relevant or effective in those reached, and thus addressing both the "access gap" and "quality gap" is instrumental to reducing suicide deaths and improving mental health outcomes [59]. And because health and related inequities and disparities often start early in life and follow one forward, often along racial, ethnic, and/or socioeconomic lines, we must utilize both early childhood prevention efforts and strive to reduce the demonstrated disparities that frequently arise in the mental healthcare of children and young adults [60]. Further, 
we must better understand individuals' potential suicide risk factors and motivations, identified or unidentified mental health conditions, or other chronic or acute life stressors and struggles, that may be in need of timely recognition and intervention before suicide occurs. We must therefore strive to do better in identifying and reaching these individuals in need of assistance, before it is too late. Toward this goal, an excellent and detailed CDC technical package on suicide prevention comments on the high suicide rates among the NHW and AIAN populations [61], and together with others' work [62], recommends a comprehensive and integrated range of multi-factorial approaches for identifying those in need and strengthening access to mental health care across all groups, with the goal of reducing rates of depression and suicide in the US population [61, 62].

In addition, with the United States' rising need for mental health treatment, we must address the pronounced shortage of mental health professionals. In the US, $27 \%, 35 \%$, and $80 \%$ of metropolitan, micropolitan, and non-core (i.e. the most rural) counties, respectively, lack a psychiatrist [63]. Similar trends in shortages exist for psychologists and psychiatric nurse practitioners. Non-core counties consistently have the lowest number of mental health professionals per capita. Across all geographic areas, metropolitan counties (on average) in only five of the nine (5/9) geographic census regions met benchmarks for the ideal number of behavioral health providers needed per 100,000 adults. For micropolitan counties, this ratio was $1 / 9$ census regions meeting provider benchmarks, and 0/9 for non-core counties [63]. Lower income or poverty are risk factors for both increased depression and reduced access to or utilization of care, which represents a complex paradox for delivering effective care in both rural and urban environments. Additionally, although number of providers per capita increases with urbanicity, there are likely to be other risk factors for mental health and suicide, and/or contributors to the access gap, that are more common to either the urban or rural environments, such as socio-cultural 
factors and differential access to firearms, all of which are areas that require better understanding and improved solutions that can be tailored both individually and by geography.

Another component of this "access gap" and a putative contributing factor to the rising US suicide rates since 1999, is the significant $37 \%$ reduction in psychiatric beds from 35 beds per 100,000 population in 1999 to 22 beds per 100,000 in 2013 [64, 65]. Indeed only 4 out of 35 Organization for Economic Cooperation and Development (OECD) countries (Italy, Chile, Mexico, and Turkey) have less psychiatry beds than the US. Psychiatric inpatient care is vital for reducing suicide risk during acute social crises and during acute relapse for severe mental illness. The increasingly limited access to acute inpatient care in the US may have resulted in acutely unwell mental health patients being denied essential and potentially life-saving acute treatment, thus putting them at greater risk for suicidal behavior.

Because of these issues, improving both the quantity and quality of community mental health services is critically important. While and colleagues (2012) examined the implementation of key service recommendations by providers of mental health services in England and Wales [66]. They examined the number of recommendations implemented and suicide rate before and after implementation. They also investigated the relative impact of individual recommendations on suicide risk in specific clinical subgroups. The suicide death rate was $17 \%$ lower under comprehensive approaches. The biggest falls in suicide were in services with the most deprived catchment areas [66].

Reducing the Quality Gap: Mental health care, once accessed, must be effective, and current evidence indicates that the "quality gap" [59] encountered in such care may sometimes be considerable. In a review of 1990 to 2015 data from Australia, Canada, England, and the US, Jorm and colleagues found "that the prevalence of mood and anxiety disorders and symptoms has not 
decreased [in these countries], despite substantial increases in the provision of treatment, particularly antidepressants" [59]. Furthermore, they evaluated several hypotheses for this apparent lack of improvement, and found the most support for their hypothesis "that much of the [mental health] treatment provided does not meet the minimal standards of clinical practice guidelines and is not targeted optimally to those in greatest need," a two-component problem that they termed the "quality gap" which they suggest must be overcome in order to reduce prevalence of common mental health disorders [59]. However they emphasize, and we reiterate, that: "In pointing out that there have not been population mental health gains, we are not suggesting that pharmacological and psychological treatments for common mental disorders do not work. There is abundant evidence from systematic reviews of randomized controlled trials that they do. Rather, this review indicates that there may have been problems of implementation or other factors that may have counteracted their impact" [59]. Indeed, a comprehensive systematic review of numerous studies evidences the apparent efficacies of both antidepressants (as well as a few other drugs) and various psychotherapeutic approaches for suicide prevention [67]. Thus both pharmacologic and psychotherapeutic approaches are crucial and potentially life-saving tools for suicide prevention, particularly when individually tailored and optimally applied (see next section), and the US must close the access and quality gaps by making sure those most at risk are identified and receive effective mental health treatment. To close these gaps, we must do a better job of identifying and mitigating the barriers and other factors that are resulting in both the "access gaps" (i.e. delivery of care to those who need it) and the "quality (or treatment) gaps" (i.e. quality or efficacy of care delivered), and thus preventing optimal mental health outcomes.

Personalized medicine for suicide prevention: Perhaps contributing to this "quality gap," evidence indicates that over time, the proportion of patients receiving medication alone for 
depression treatment (i.e. without accompanying psychotherapy) has grown, as has the proportion of patients prescribed antidepressants without an accompanying psychiatric diagnosis or for milder or subclinical symptoms [59]. These trends may in part reflect increased "reach" of mental health treatment to those demographics that typically utilize primary medical care or emergency rooms whereas more at-risk individuals with severe depression in medically underserved populations are likely to have lesser access to antidepressants or other mental health treatment. One could also hypothesize that these changing trends may contribute to why in the early years of SSRI availability in the US, there appeared to be an inverse correlation between SSRI (fluoxetine) prescriptions and suicides [34], whereas more recently both antidepressant prescriptions [35] and suicides (Figure 1) are rising in the US. However, finding support for this hypothesis would imply causal links between antidepressants (or psychotherapies) and suicide reduction that have been very difficult to establish due to: 1) the nature of the studies required, 2) the highly multi-factorial nature of suicide [61] including its relationship to psychiatric diseases other than depression (such as schizophrenia and substance abuse), impulsivity, or other triggers, and 3) the tremendous variability of individuals' response and adherence to antidepressants and psychotherapies.

Hence there is a growing consensus that better understanding antidepressants' (and psychotherapies') effects and variability at the individual level will be imperative to developing more effective, personalized treatments for depression and suicide prevention - and in doing so, may offer greater insights into the many paradoxes and conflicting results found in the extensive literature and clinical experience on antidepressants, depression, and suicide. At the individual level, there is much variability as to whether a particular antidepressant drug, even within the same class, may help a specific person's depression, and/or may prevent or even promote suicidal ideation or behavior. In many cases, our understanding of the full range of any given 
antidepressant's mechanistic and functional actions may be incomplete, or may evolve with time. An abundance of literature and clinical and anecdotal experience indicates that dependent on many variables - e.g. an individual's age, gender, and their own unique pharmacophysiology and genetics - the same drug may have a particular effect in one individual, but a differing or no clinically apparent therapeutic effect in another.

These variable data highlight the need for more personalized and precision medicine approaches in depression, suicide, and psychiatric care. Pharmacogenomics - or "the identification of genome variants that influence drug effects, typically via alterations in a drug's pharmacokinetics . . . or via modulation of a drug's pharmacodynamics" [68] - can be used to identify predictors of response to existing therapies, and identify conceptually novel targets or treatments for depression and suicide prevention [69]. For antidepressants, some encouraging pharmacogenomic discoveries with actionable impacts on dosing or drug selection have been made but obstacles to widespread clinical application still remain [69-72], and instances where pharmacogenomic evidence provides us with practicable clinical guidance for any particular patient unfortunately remains very much the exception rather than the rule. Moreover there is much room for improved understanding of the genetics, functional neuropharmacology, and neurobiology (e.g. biomarkers? [73]) of suicide and suicide prevention. In a comprehensive paper that elegantly demonstrates the potential of precision medicine efforts to combat suicidality, Niculescu and colleagues identified several novel blood gene expression biomarkers, and reinforced the validity of others previously identified, that were predictive for suicidal ideation and for future hospitalizations for suicidality [74]. Moreover, they identified completely novel gene biomarkers and reinforced previously known biomarkers that were predictive for suicidality in certain subgroups, e.g. males with depression or males with bipolar disorder. They also explored 
and identified diagnostic potential and conducted biological pathway and network analyses of key biomarkers, and used connectivity map (CMAP) analysis to identify known (i.e. potentially repurposable) drugs with gene expression profile effects opposite to their identified suicide biomarkers' gene signatures, and thus having strong and newly identified therapeutic potential for suicide prevention.

Finally, recent results with repurposed drugs that may act more quickly or efficaciously than traditional antidepressants - such as ketamine (an anesthetic) for refractory depression and suicide risk reduction - are promising and have led to an explosion of interest in developing novel therapeutics with similar known mechanisms of actions [75-79], and may lead to identification of additional novel targets if further therapeutic mechanisms of action are uncovered. These evolving findings with ketamine are consistent with and complementary to existing evidence that some of the drugs with the most well-demonstrated (e.g. lithium, clozapine; [67]) or likely (e.g. valproate; $[67,80])$ anti-suicide effects are also not classified as antidepressants - once again highlighting the complex, multi-factorial nature of suicide (and depression, particularly refractory depression), and the need for more personalized precision medicine in psychiatric treatments for these diseases.

The "prevention gap": Jorm et al. also propose a "prevention gap" resulting from too few resources and efforts devoted to reducing incidence of mental health disorders through prevention [59]. Indeed, estimates suggest that $20 \%$ of US children have a diagnosable mental health condition, and "[m]ore than half of mental illness emerges before age 14" [81], yet $85 \%$ of those needing treatment do not receive it $[60,81]$. Suicide is the second leading cause of death for 10 34 year olds, fourth leading cause of death for 35-54 year olds, and 8th leading for ages 55-64 [82]. Put another way, in the context of depression and suicidality specifically - since it is difficult to identify or reach all who may need mental health care (access gap), treatments may sometimes be 
ineffective (quality gap) or refused, and only $30-48 \%$ of suicides (depending on racial/ethnic group) involve a previously identified mental health condition [41] - then it is imperative that preventative measures are considered equal first-line defenses for reducing suicide deaths, and much work remains to be done in this important area.

\section{Is increased or unsafe (disparate) access to firearms a health equity issue?}

In this paper, we highlight how increased access to firearms is associated with higher suicide rates, with noted disparities in both based on geography and other factors. As such, increased or avoidable access to highly lethal means might reasonably be viewed as an environmental determinant to health that is associated with increased suicide risk, thus creating health disparities or "avoidable inequalities" [1] that promote health inequity. Indeed, a health disparity is "a particular type of health difference that is closely linked with social, economic, and/or environmental disadvantage" $[1,83]$, and access to firearms certainly confers a distinct "environmental disadvantage" when it comes to suicide risk. The abundance of evidence strongly suggests that reducing access to lethal means, particularly firearms, will reduce suicide deaths and save lives, thus advancing health equity, i.e. "attainment of the highest level of health for all people" $[1,83]$.

The "prevention gap" and access to lethal means: The preponderance of studies now find "strong evidence that restricting access to lethal means is associated with a decrease in suicide and that substitution to other methods appears to be limited. This is clearly a major strategy to be integrated in national suicide prevention plans" [67]. Moreover, unfortunately yet undeniably, firearms are the most employed lethal means in suicide and account for over half of US suicide deaths in any given year, more than all other lethal means combined [3]. In some populations, as 
many as $89 \%$ of suicides occur by gun (Table 2 ), which is a staggering figure. By simple math, this means that strategically and effectively employed firearm safety measures are, by themselves, the sole preventative action most likely to have the greatest impact on reducing suicide deaths.

Access to firearms and suicide rates: Of the 47,173 suicides in the United States in 2017, $23,854(51 \%)$ were by firearm [5]. Easy, immediate access to firearms in the home places household members at 3-5 fold increased risk for suicide [84-86], up to 9-fold increased risk with unsafe storage practices [84], and at 17-fold increased risk for suicide by firearm [85]. Further, this "heightened risk of suicide [with household firearm ownership] is not explained by a higher risk of psychopathology among gun-owning families" [87] (and see [88]). Moreover, "persons with a gun in the home were [are] more likely than others to use a gun to [die by] suicide and less likely than others to [die by] suicide by means of drug overdose, hanging, or other method other than a gun" [85]. Population (household) rates of gun ownership are strongly associated with overall suicide rates, gun suicide rates, and percentage of suicides by gun in the US (Table 3 and Figure 3) [89-91], even when prescription rates of antidepressants are considered [92]. Evidence suggests that $33 \%-80 \%$ of suicidal acts are impulsive [93], and among individuals making nearlethal suicide attempts, $70 \%$ of those made the decision within an hour of the attempt, and $24 \%$ within 5 minutes of the attempt [94]. And "more than $90 \%$ of people who survive a suicide attempt, including attempts that were expected to be lethal ... do not go on to die by suicide" [93] - thus strongly supporting the emerging understandings that suicide is not inevitable, and that only very rarely will suicide attempters substitute another lethal means if one is not readily available [95]. Since 1999, suicides have accounted for 55\%-64\% of all firearm deaths, with that number being $\geq$ $60 \%$ since $2010[5,96]$. 


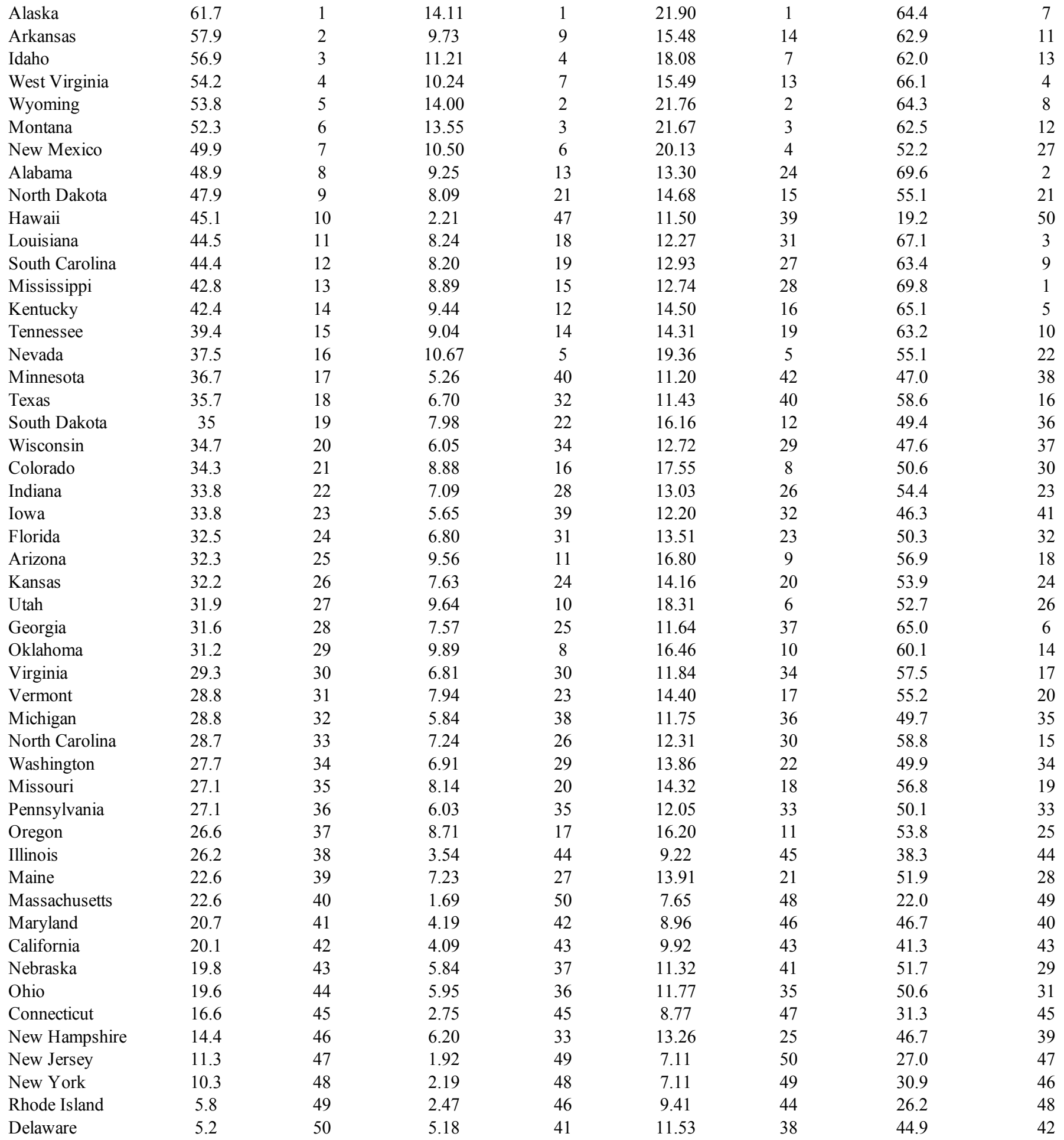

Table 3: State Gun Ownership versus Gun Suicides, All Suicides, and Percent Suicides by Gun.

All data is age-adjusted deaths per 100000 (2000 US population) and cumulative 1999-2017 data [5], except surveybased gun ownership by state [97], and percent gun suicides (= gun suicide rate/all suicide rate). 

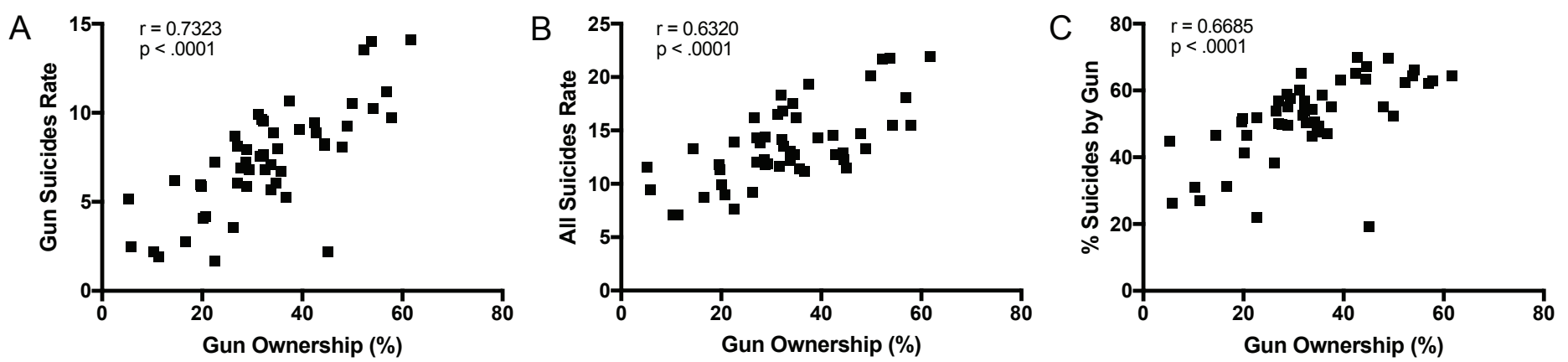

Figure 3: State Gun Ownership versus Gun Suicides, All Suicides, and Percent Suicides by Gun. Spearman correlation analysis for nonparametric data was performed on state gun ownership rates versus state A) Gun suicide rate, B) All suicide rate, and C) Percent suicides by gun. All data was from Table $3 . \mathrm{P}<.0001$ for all spearman correlation coefficients $(r)$ shown.

Consistent with this data, firearm suicide rates also appear to track household gun ownership rates across racial/ethnic groups. In one study, Riddell et al. explored the relationships between rates of firearm suicide and reported household firearm ownership in NHW and NHB, by state, and concluded that "state gun prevalence was strongly tied to firearm suicide for both black and white men" [98]. Furthermore, of US adults surveyed in April 2017, 49\% (NHW), 32\% (NHB), and 21\% (HISP) reported the presence of a gun in their household [99]. API consistently have the lowest reported household gun ownership, estimated at 15\% in one survey [100], whereas little household gun ownership data is available for AIAN but was reported at $53 \%$ in a small sample size (148 respondents) from two localities in Alaska, slightly under the percentage of NHW for the regions sampled [101]. Similarly, firearm suicide rates (all genders, all ages, per 100,000 age-adjusted population) for these groups in 2017 follow the same rank order: 9.1 (NHW), 8.4 (AIAN), 3.4 (NHB), 2.5 (HISP), and 1.7 (API). These data, together with Tables 2-3 and Figure 3, suggest that gun (and overall) suicide rates appear to closely track gun ownership rates across different populations.

Geographic differences in firearm ownership, both internationally and intranationally in the US, are another likely factor in the refractory US suicide rate. US gun ownership is very high 
by international standards, and the overall US rate of firearm suicide (6.9 per 100,000 age-adjusted population in 2017; 6.1 in 2010 for comparison below) [3] is far higher than any other high-income countries [102], and far higher than rates in countries with stronger firearm safety measures such as the UK (0.2 per 100000), Australia (0.8), New Zealand (1.0), and Canada (1.7) [102]. Here in the US, suicide rates rise significantly with increasing rurality (i.e. lowest in cities, higher in towns/small cities, highest in rural areas) (Figure 2, Tables 1-3) [3], where gun ownership rates are higher (Table 3). Accordingly, the rural states consistently have the highest rates of gun ownership, total suicides, and firearm suicides in the USA, whereas the states with lowest household gun ownership (and usually more protective firearm laws), which are often more densely populated, tend to have lower suicide rates (Table 3) [103-106]. Indeed, for each state, survey based estimates of gun ownership (\% individuals) are strongly and significantly correlated with gun suicide rate, overall suicide rate, and percent suicides by gun within the state (Figure 3). This is consistent with others' validation of percent suicides by gun as a proxy measure for prevalence of household firearm ownership [107], although in our analysis using survey-based data for state gun ownership rates [97] together with cumulative (1999-2017) age-adjusted data for statewide suicide and firearm suicide rates [5], we found the strongest correlation between gun ownership and gun suicide rates $(\mathrm{r}=.7323, \mathrm{p}<.0001)$, followed by $\%$ suicides by guns $(\mathrm{r}=.6685$, $\mathrm{p}<.0001)$, and overall suicides $(\mathrm{r}=.6320, \mathrm{p}<.0001)$.

Males, those living in rural states or areas, and select other populations such as AIAN and NHW have higher suicide and gun suicide rates - and typically higher firearm ownership - versus other groups (Figure 2, Tables 1-3). Elderly men also have disproportionately high gun suicide rates and percent suicides by gun, and NHB males match NHW males in having the highest percent suicides by gun (despite NHB males having relatively lower overall suicide rates) (Table 2). Rural 
males making a living in agriculture may also be at particular risk $[108,109]$. For these reasons alone, some groups may see more relative benefit from firearm safety measures, but all groups will benefit from such measures by reduced suicide deaths. In addition, while firearms typically account for $\geq 50 \%$ of suicides across all genders, females die by suicide at a lower rate than males, and less frequently with firearms than do males (typically $<50 \%$ of female suicides are by firearm, versus $>50 \%$ for males) (Table 2) [110]. Therefore additional strategies to reduce access to other lethal means (besides firearms) will also help minimize suicide and maximize public health for all groups, but with a relatively greater benefit for women.

Identifying the most effective firearm safety measures: We approach this topic from purely a public health perspective. Based upon the preponderance of evidence we wish to emphasize the point, as others have, that reducing access to lethal means will almost certainly save many lives that might otherwise be lost to suicide [67, 90, 91, 95, 106, 111]. Reducing access to lethal means as involves firearms in particular can take many forms, ranging from individual to community to legislative initiatives.

Universal background checks (UBCs) limit firearm purchases to only individuals of qualified age, and without other risk factors such as substance abuse, threats to self or others due to mental illness, or onvictions of crimes of violence or domestic violence. Anestis \& Anestis (2015) found states that utilize UBCs had about a 50\% lower rate of firearm suicides [112]. By limiting easy/immediate acquisition of firearms, other similar regulations that delay or deter gun purchases, such as mandatory waiting periods or permit requirements, are also linked to reductions in suicide deaths. Specifically, waiting periods "lead to a $7-11 \%$ reduction in gun suicides ... which is equivalent to $22-35$ fewer gun suicides per year for the average state" [113]. Permit to purchase (PTP) laws are similar to UBC laws as they typically require a 
background check to obtain a permit, and are associated with a $15 \%$ reduction in firearm suicide rate [114]. Further, this study by Crifasi et al. estimated the effects of changes in PTP handgun laws in Connecticut and Missouri. Connecticut adopted a permit-to-purchase handgun law in October, 1995 that included mandated background PTP for all handgun transfers, contingent on passing a background check and safety training course. Missouri had a PTP handgun law since the 1920s that required a PTP for all handgun sales, with permits obtained from sheriff and good for 30 days. This law was repealed in Aug. 28, 2007. In CT, firearm suicide rates declined by $15 \%$ in the decade after the PTP law was introduced, but rose by $16 \%$ in the five years after the PTP law was repealed in Missouri [114].

The CDC's technical package on suicide prevention recommends safe (e.g. locked) storage practices for firearms and other lethal means (e.g. drugs and toxins) as preventative measures for at-risk individuals, and provides evidence that such safe storage practices have been found effective for reducing suicide risk [61]. In support, others have presented comprehensive metaanalyses of approaches to reducing access to various lethal means that have been demonstrably effective for reducing suicide risk [67]. Regarding firearms in particular, significant evidence indicates that safe storage helps reduce suicide risk $[84,90,115]$, with suicide risk increasing predictably with each gradation of unsafe storage. For example, versus "no guns in the home," having "any gun kept unlocked" or "any gun kept loaded" increased all-means suicide risk by 5.6fold and 9.2-fold respectively [84]. Others found that adolescent suicide was four times more likely in homes with unlocked and loaded firearms, versus homes with locked and unloaded firearms $[116,117]$. Policies that focus on responsible firearm storage such as Child Access Prevention laws are associated with a $19 \%$ decrease in gun suicides among ages $10-14$, and an $11 \%$ decrease among ages 14-17 [118-120]. 
In part for these reasons, firearm personalization or "smart gun" technology, which limits firearm use to the owner or permitted user, is a promising and evolving technology with potential to reduce suicide deaths, perhaps especially youth firearm suicides [91]. Several excellent overviews of the range of firearm safety measures that have been shown effective for reducing suicide risk are available $[67,90,91]$.

Thus where firearms are present, maximizing use of both safe storage practices (i.e. locked, unloaded, and with ammunition stored separately) and all other available firearm safety measures is critical, and can significantly reduce suicide risk compared to less safe firearm practices. At the same time, perfect or "ideal" safe-storage compliance and gun safety in all households with firearms is both difficult to achieve and subject to opinion [121, 122], and even with "all guns locked up" suicide risk is still 2.4 times higher than in households without firearms [84]. Hence supplementary legislative firearm safety measures may further help minimize suicide deaths and maximize public health and health equity.

The heartbreakingly continuous reports of mass shootings and high-profile suicides in the national media, along with the accompanying public-majority pressure, have finally helped overcome some of the long-standing legislative resistance and inertia in the form of increasing numbers of state-level common-sense "red flag" firearm safety laws, intended to temporarily remove or restrict firearm ownership from individuals deemed (by an adjudicated process) to be a risk to themselves or others $[123,124]$. Extreme risk protection orders (ERPOs), lethal violence protection orders (LVPOs), and gun violence restraining orders (GVROs) temporarily prohibit access to firearms (purchase or possession) by high-risk individuals. These programs enable law enforcement, health professionals, and families to intervene when individuals are dangerous to themselves or others. ERPOs or GVROs were associated with $7.5 \%$ reduction of firearm suicide 
rate in Indiana, and a 14\% reduction in Connecticut [125].

Clinicians can also provide lethal means counseling to high-risk patients and their family or friends support systems, to limit access until they are no longer at elevated risk [126]. One such program, Counseling on Access to Lethal Means (CALM), trained emergency department providers to counsel families of youths at high risk for suicide on restricting home access to lethal medications, alcohol, and firearms. This study found that, of the parents contacted at follow up, $76 \%$ reported all medications in the home were locked as compared to fewer than $10 \%$ at the time of the first visit, and 100\% indicated guns in the home were currently locked, as compared to $67 \%$ reporting this at the time of the initial visit [127]. These programs have great potential to reduce youth and adult suicide rates through educational programs regarding safe storage practices of potentially lethal means, particularly around individuals at high risk of self-harm.

Awareness [128] or legislative [114] campaigns to help prevent sales of firearms to at-risk individuals may also be useful. Directly engaging key stakeholders in, for example, gun shop prevention programs aimed at providing suicide prevention literature within the store, and educating gun shop owners on spotting suicide risks so that they may then take safe and appropriate preventive action (e.g. refusing a sale, talking with the customer and referring to suicide prevention resources if appropriate, etc.), have a track record of success and hold much promise [129]. Increased presence of gun shops is associated with higher suicide rates, underscoring the need for more lethal means safety programs of this nature [48]. These are all very positive steps in the right direction with demonstrated efficacy in reducing suicide deaths $[114,125,130]$, and thus the importance of these measures for improving public health cannot be overstated.

At the same time, only $30-48 \%$ of suicides (depending on racial/ethnic group) involve a previously identified mental health condition [41], which leaves $52 \%-70 \%$ of suicides as unlikely 
to be pre-identified or actionable by "red flag" firearm laws. Perhaps not surprisingly then, by some reports, "empirical analysis suggest[s] that firearms regulations which function to reduce overall gun availability have a significant deterrent effect on male suicide, while regulations that seek to prohibit high risk individuals from owning firearms have a lesser effect" [131]. So in some cases, additional proactive safety measures to reduce access to lethal means may be necessary to truly minimize suicide deaths and maximize public health, and there are many rigorous analyses suggesting that these kinds of additional safety measures are effective for reducing suicides, saving lives, and promoting health equity $[90,91,95,106]$.

Also encouraging is the recent legislative guidance or "clarification" that the Dickey Amendment does not, in fact, prevent the use of federal funds for research on gun violence. A careful reading of the Dickey Amendment would indeed agree that, strictly speaking, it never did. Rather, it simply stated "That none of the funds made available for injury prevention and control at the Centers for Disease Control and Prevention may be used to advocate or promote gun control" - i.e. it only prohibited firearm control advocacy with those federal CDC funds [132]. However the common misconception that the Dickey Amendment prohibited or "banned" use of federal funds for gun violence research probably did not arise by accident. Rather, passage of the Amendment in 1996 was accompanied by a $\$ 2.6$ million reduction in the CDC's budget, equivalent to the exact amount the CDC had spent on firearm related research the previous year [133]. The message seemed clear and effectively squelched any subsequent federally funded research on gun violence, including nearly all extramural $\mathrm{NIH}$-funded research on gun violence despite the massive public health problem that it represents, putatively because no federal agency has been willing to risk the potential political or budgetary repercussions should they fund or participate in such research $[134,135]$. (The sparse NIH funds that have gone toward investigating gun violence over 
the years are a positive step forward [136], but still a drop in the bucket compared to what the NIH spends on equivalent public health threats [137-139].) Therefore, although the recent legislative "clarification" on what is permitted under the Dickey Amendment is a welcome step in the right direction, in effect nothing has changed, and it remains to be seen whether this recent clarifying guidance will translate to increased availability and distribution of federal funds for research on firearm suicide and other gun violence.

Questions of practicability aside, there is "overwhelming evidence linking firearm availability and suicide risk" [140], and the preponderance of evidence demonstrates that from a public health standpoint, researching and then implementing the most effective firearm safety measures will significantly reduce suicide deaths in the US, and without them achieving maximum suicide reduction and public health gains, and health equity, will unfortunately be highly unlikely. Encouragingly, there have been some small but important steps in the right direction, and the majority of people want to get on board with improving safety, reducing deaths, and maximizing individual and public health $[139,141]$.

\section{Conclusions}

High and rising US suicide rates are a public health crisis, with no signs of abating, especially among select disproportionately at-risk populations including children and young adults, the elderly, veterans, AIAN and NHW, inhabitants of rural areas, and those with increased access to firearms. Many of these deaths are likely to be preventable, with increased funding for suicide research and prevention, more accessible and effective treatments for depression, and common-sense lethal means reductions for those most at risk. A very recent report by staff of the U.S. Congress Joint Economic Committee (JEC), entitled "Guns and Suicide," has highlighted 
findings and drawn conclusions similar to ours herein [142], providing hope that these issues may finally receive greater and much needed legislative attention. We hope that increased national prioritization of all these critical areas can help stem the rapidly rising tide of US suicides and improve health equity.

\section{Acknowledgments:}

This work was supported by institutional funds from the State University of New York (SUNY) Upstate Medical University. This paper is subject to the SUNY Open Access Policy. 


\section{References:}

1. National Stakeholder Strategy for Achieving Health Equity. Rockville, MD: By: National Partnership for Action to End Health Disparities, US Department of Health and Human Services, Office of Minority Health; 2011 (https://minorityhealth.hhs.gov/npa/files/Plans/NSS/CompleteNSS.pdf). 2. Hedegaard H, Curtin SC, Warner M. Suicide Mortality in the United States, 1999-2017. NCHS Data Brief. 2018;(330):1-8. Epub 2018/12/01. PubMed PMID: 30500324.

3. Ivey-Stephenson AZ, Crosby AE, Jack SPD, Haileyesus T, Kresnow-Sedacca MJ. Suicide Trends Among and Within Urbanization Levels by Sex, Race/Ethnicity, Age Group, and Mechanism of Death United States, 2001-2015. MMWR Surveill Summ. 2017;66(18):1-16. Epub 2017/10/06. doi: 10.15585/mmwr.ss6618a1. PubMed PMID: 28981481; PubMed Central PMCID: PMCPMC5829833. 4. CDC Fact Sheet: Health Disparities in Suicides. Atlanta, GA: By: Centers for Disease Control and Prevention (CDC), US Department of Health and Human Services; 2011 (https://www.cdc.gov/minorityhealth/chdir/2011/factsheets/suicide.pdf). 5. $\quad$ https://webappa.cdc.gov/sasweb/ncipc/mortrate.html.

6. Curtin SC, Heron M. Death rates due to suicide and homicide among persons aged 10-24: United States, 2000-2017. NCHS Data Brief, no 352 Hyattsville, MD: National Center for Health Statistics. 2019.

7. Bostwick WB, Meyer I, Aranda F, Russell S, Hughes T, Birkett M, et al. Mental health and suicidality among racially/ethnically diverse sexual minority youths. Am J Public Health. 2014;104(6):1129-36. Epub 2014/05/16. doi: 10.2105/AJPH.2013.301749. PubMed PMID: 24825217; PubMed Central PMCID: PMCPMC4062032.

8. di Giacomo E, Krausz M, Colmegna F, Aspesi F, Clerici M. Estimating the Risk of Attempted Suicide Among Sexual Minority Youths: A Systematic Review and Meta-analysis. JAMA Pediatr. 2018;172(12):1145-52. Epub 2018/10/12. doi: 10.1001/jamapediatrics.2018.2731. PubMed PMID: 30304350 .

9. Hottes TS, Bogaert L, Rhodes AE, Brennan DJ, Gesink D. Lifetime Prevalence of Suicide Attempts Among Sexual Minority Adults by Study Sampling Strategies: A Systematic Review and MetaAnalysis. Am J Public Health. 2016;106(5):e1-12. Epub 2016/04/07. doi: 10.2105/AJPH.2016.303088. PubMed PMID: 27049424; PubMed Central PMCID: PMCPMC4985071.

10. Johns MM, Lowry R, Rasberry CN, Dunville R, Robin L, Pampati S, et al. Violence Victimization, Substance Use, and Suicide Risk Among Sexual Minority High School Students - United States, 2015-2017. MMWR Morb Mortal Wkly Rep. 2018;67(43):1211-5. Epub 2018/11/02. doi: 10.15585/mmwr.mm6743a4. PubMed PMID: 30383738.

11. King M, Semlyen J, Tai SS, Killaspy H, Osborn D, Popelyuk D, et al. A systematic review of mental disorder, suicide, and deliberate self harm in lesbian, gay and bisexual people. BMC Psychiatry. 2008;8:70. Epub 2008/08/19. doi: 10.1186/1471-244X-8-70. PubMed PMID: 18706118; PubMed Central PMCID: PMCPMC2533652.

12. Marshall A. Suicide Prevention Interventions for Sexual \& Gender Minority Youth: An Unmet Need. Yale J Biol Med. 2016;89(2):205-13. Epub 2016/06/30. PubMed PMID: 27354846; PubMed Central PMCID: PMCPMC4918883.

13. Mereish EH, Sheskier M, Hawthorne DJ, Goldbach JT. Sexual orientation disparities in mental health and substance use among Black American young people in the USA: effects of cyber and biasbased victimisation. Cult Health Sex. 2019:1-14. Epub 2019/01/03. doi:

10.1080/13691058.2018.1532113. PubMed PMID: 30601086.

14. Puckett JA, Horne SG, Surace F, Carter A, Noffsinger-Frazier N, Shulman J, et al. Predictors of Sexual Minority Youth's Reported Suicide Attempts and Mental Health. J Homosex. 2017;64(6):697-715. Epub 2016/06/09. doi: 10.1080/00918369.2016.1196999. PubMed PMID: 27268386.

15. Shadick R, Backus Dagirmanjian F, Barbot B. Suicide Risk Among College Student. The Intersection of Sexual Orientation and Race. Crisis. 2015;36(6):416-23. Epub 2015/12/10. doi: 10.1027/0227-5910/a000340. PubMed PMID: 26648229. 
16. Fish JN, Rice CE, Lanza ST, Russell ST. Is Young Adulthood a Critical Period for Suicidal Behavior among Sexual Minorities? Results from a US National Sample. Prev Sci. 2018. Epub 2018/03/30. doi: 10.1007/s11121-018-0878-5. PubMed PMID: 29594980.

17. Sexton MB, Davis MT, Anderson RE, Bennett DC, Sparapani E, Porter KE. Relation between sexual and gender minority status and suicide attempts among veterans seeking treatment for military sexual trauma. Psychol Serv. 2018;15(3):357-62. Epub 2018/08/07. doi: 10.1037/ser0000207. PubMed PMID: 30080095.

18. Blosnich JR, Mays VM, Cochran SD. Suicidality among veterans: implications of sexual minority status. Am J Public Health. 2014;104 Suppl 4:S535-7. Epub 2014/08/08. doi: 10.2105/AJPH.2014.302100. PubMed PMID: 25100418; PubMed Central PMCID: PMCPMC4151905. 19. Haas AP, Lane AD, Blosnich JR, Butcher BA, Mortali MG. Collecting Sexual Orientation and Gender Identity Information at Death. Am J Public Health. 2018:e1-e5. Epub 2018/12/21. doi: 10.2105/AJPH.2018.304829. PubMed PMID: 30571294.

20. https://www.mentalhealth.va.gov/docs/datasheets/2019/2019 National Veteran Suicide Prevention_Annual Report 508.pdf.

21. Sall J, Brenner L, Millikan Bell AM, Colston MJ. Assessment and Management of Patients at Risk for Suicide: Synopsis of the 2019 U.S. Department of Veterans Affairs and U.S. Department of Defense Clinical Practice Guidelines. Ann Intern Med. 2019;171(5):343-53. Epub 2019/08/27. doi: 10.7326/M19-0687. PubMed PMID: 31450237.

22. https://www.healthquality.va.gov/guidelines/MH/srb/.

23. Hogan M. Veteran Suicide: Not Just a VA Issue; It's a U.S. Issue. Ann Intern Med. 2019;171(5):372-3. Epub 2019/08/27. doi: 10.7326/M19-1796. PubMed PMID: 31450241.

24. Department of Veterans Affairs. Suicide among Veterans and other Americans 2001-2014. https://www.mentalhealth.va.gov/docs/2016suicidedatareport.pdf. Washington, DC, Office of Suicide Prevention,. 2016.

25. https://www.va.gov/ve/docs/outreachToolkitPreventingVeteranSuicideIsEveryonesBusiness.pdf.

26. Speer M, Phillips MA, Winkel T, Wright W, Winkel N, Reddy S. "Serving Those Who Serve: Upstream Intervention And The Uphill Battle Of Veteran Suicide Prevention In The US, " Health Affairs Blog, July 11, 2019. DOI:10.1377/hblog20190709.197658.

27. https://www.whitehouse.gov/presidential-actions/executive-order-national-roadmap-empowerveterans-end-suicide/.

28. Kegler SR, Stone DM, Holland KM. Trends in Suicide by Level of Urbanization - United States, 1999-2015. MMWR Morb Mortal Wkly Rep. 2017;66(10):270-3. Epub 2017/03/17. doi:

10.15585/mmwr.mm6610a2. PubMed PMID: 28301448; PubMed Central PMCID: PMCPMC5657870.

29. Rossen LM, Hedegaard H, Khan D, Warner M. County-Level Trends in Suicide Rates in the U.S., 2005-2015. Am J Prev Med. 2018;55(1):72-9. Epub 2018/05/19. doi:

10.1016/j.amepre.2018.03.020. PubMed PMID: 29773489; PubMed Central PMCID: PMCPMC6038117. 30. Fontanella CA, Hiance-Steelesmith DL, Phillips GS, Bridge JA, Lester N, Sweeney HA, et al. Widening rural-urban disparities in youth suicides, United States, 1996-2010. JAMA Pediatr. 2015;169(5):466-73. Epub 2015/03/10. doi: 10.1001/jamapediatrics.2014.3561. PubMed PMID: 25751611; PubMed Central PMCID: PMCPMC4551430.

31. Singh GK, Siahpush M. Increasing rural-urban gradients in US suicide mortality, 1970-1997. Am J Public Health. 2002;92(7):1161-7. Epub 2002/06/27. doi: 10.2105/ajph.92.7.1161. PubMed PMID: 12084702; PubMed Central PMCID: PMCPMC1447208.

32. https://www.cdc.gov/nchs/data access/urban_rural.htm.

33. https://www.hhs.gov/answers/mental-health-and-substance-abuse/does-depression-increase-riskof-suicide/index.html.

34. Milane MS, Suchard MA, Wong ML, Licinio J. Modeling of the temporal patterns of fluoxetine prescriptions and suicide rates in the United States. PLoS Med. 2006;3(6):e190. Epub 2006/06/14. doi: 10.1371/journal.pmed.0030190. PubMed PMID: 16768544; PubMed Central PMCID: PMCPMC1475655. 
35. Pratt LA, Brody DJ, Gu Q. Antidepressant Use Among Persons Aged 12 and Over:United States,2011-2014. NCHS Data Brief. 2017;(283):1-8. Epub 2017/11/21. PubMed PMID: 29155679. 36. Dillard DA, Avey JP, Robinson RF, Smith JJ, Beals J, Manson SM, et al. Demographic, Clinical, and Service Utilization Factors Associated with Suicide-Related Visits among Alaska Native and American Indian Adults. Suicide Life Threat Behav. 2017;47(1):27-37. Epub 2016/04/26. doi: 10.1111/sltb.12259. PubMed PMID: 27111633; PubMed Central PMCID: PMCPMC5079841.

37. Weinberger AH, Gbedemah M, Martinez AM, Nash D, Galea S, Goodwin RD. Trends in depression prevalence in the USA from 2005 to 2015: widening disparities in vulnerable groups. Psychol Med. 2018;48(8):1308-15. Epub 2017/10/13. doi: 10.1017/S0033291717002781. PubMed PMID: 29021005.

38. McMillan KA, Enns MW, Asmundson GJ, Sareen J. The association between income and distress, mental disorders, and suicidal ideation and attempts: findings from the Collaborative Psychiatric Epidemiology Surveys. J Clin Psychiatry. 2010;71(9):1168-75. Epub 2010/05/06. doi:

10.4088/JCP.08m04986gry. PubMed PMID: 20441719.

39. Spicer RS, Miller TR. Suicide acts in 8 states: incidence and case fatality rates by demographics and method. Am J Public Health. 2000;90(12):1885-91. Epub 2000/12/09. doi: 10.2105/ajph.90.12.1885. PubMed PMID: 11111261; PubMed Central PMCID: PMCPMC1446422.

40. Drexler M. Guns and suicide: The hidden toll.

https://www.hsph.harvard.edu/magazine/magazine article/guns-suicide/. Harvard School of Public Health. 2013:24-35.

41. Stone DM, Simon TR, Fowler KA, Kegler SR, Yuan K, Holland KM, et al. Vital Signs: Trends in State Suicide Rates - United States, 1999-2016 and Circumstances Contributing to Suicide - 27 States, 2015. MMWR Morb Mortal Wkly Rep. 2018;67(22):617-24. Epub 2018/06/08. doi:

10.15585/mmwr.mm6722a1. PubMed PMID: 29879094; PubMed Central PMCID: PMCPMC5991813.

42. Franklin JC, Ribeiro JD, Fox KR, Bentley KH, Kleiman EM, Huang X, et al. Risk factors for suicidal thoughts and behaviors: A meta-analysis of 50 years of research. Psychol Bull. 2017;143(2):187232. Epub 2016/11/15. doi: 10.1037/bul0000084. PubMed PMID: 27841450.

43. Carey B. How Suicide Quietly Morphed Into a Public Health Crisis. The New York Times, . June 8, 2018, https://www.nytimes.com/2018/06/08/health/suicide-spade-bordain-cdc.html June 8.

44. Brown L, Tucker-Seeley R. Commentary: Will 'Deaths of Despair' among Whites Change How We Talk about Racial/Ethnic Health Disparities? Ethn Dis. 2018;28(2):123-8. Epub 2018/05/05. doi: 10.18865/ed.28.2.123. PubMed PMID: 29725197; PubMed Central PMCID: PMCPMC5926855.

45. Case A, Deaton A. Rising morbidity and mortality in midlife among white non-Hispanic Americans in the 21st century. Proc Natl Acad Sci U S A. 2015;112(49):15078-83. Epub 2015/11/18. doi: 10.1073/pnas.1518393112. PubMed PMID: 26575631; PubMed Central PMCID: PMCPMC4679063.

46. Case A, Deaton A. Mortality and morbidity in the 21(st) century. Brookings Pap Econ Act. 2017;2017:397-476. Epub 2017/10/17. PubMed PMID: 29033460; PubMed Central PMCID: PMCPMC5640267.

47. Bor J, Cohen GH, Galea S. Population health in an era of rising income inequality: USA, 19802015. Lancet. 2017;389(10077):1475-90. Epub 2017/04/14. doi: 10.1016/S0140-6736(17)30571-8. PubMed PMID: 28402829.

48. Steelesmith DL, Fontanella CA, Campo JV, Bridge JA, Warren KL, Root ED. Contextual Factors Associated With County-Level Suicide Rates in the United States, 1999 to 2016. JAMA Netw Open. 2019;2(9):e1910936. Epub 2019/09/07. doi: 10.1001/jamanetworkopen.2019.10936. PubMed PMID: 31490540; PubMed Central PMCID: PMCPMC6735416.

49. Stein EM, Gennuso KP, Ugboaja DC, Remington PL. The Epidemic of Despair Among White Americans: Trends in the Leading Causes of Premature Death, 1999-2015. Am J Public Health. 2017;107(10):1541-7. Epub 2017/08/18. doi: 10.2105/AJPH.2017.303941. PubMed PMID: 28817333; PubMed Central PMCID: PMCPMC5607670.

50. Minton J, Green M, McCartney G, Shaw R, Vanderbloemen L, Pickett K. Two cheers for a small giant? Why we need better ways of seeing data: A commentary on: 'Rising morbidity and mortality in 
midlife among White non-Hispanic Americans in the 21st century'. Int J Epidemiol. 2017;46(1):356-61. Epub 2016/09/18. doi: 10.1093/ije/dyw095. PubMed PMID: 27639276; PubMed Central PMCID: PMCPMC5407174.

51. Brody DJ, Pratt LA, Hughes JP. Prevalence of Depression Among Adults Aged 20 and Over: United States, 2013-2016. NCHS Data Brief. 2018;(303):1-8. Epub 2018/04/12. PubMed PMID: 29638213.

52. Wetherall K, Daly M, Robb KA, Wood AM, O'Connor RC. Explaining the income and suicidality relationship: income rank is more strongly associated with suicidal thoughts and attempts than income. Soc Psychiatry Psychiatr Epidemiol. 2015;50(6):929-37. Epub 2015/04/22. doi: 10.1007/s00127015-1050-1. PubMed PMID: 25893994.

53. Kim JL, Kim JM, Choi Y, Lee TH, Park EC. Effect of Socioeconomic Status on the Linkage Between Suicidal Ideation and Suicide Attempts. Suicide Life Threat Behav. 2016;46(5):588-97. Epub 2016/03/19. doi: 10.1111/sltb.12242. PubMed PMID: 26991513.

54. Machado DB, Rasella D, Dos Santos DN. Impact of income inequality and other social determinants on suicide rate in Brazil. PLoS One. 2015;10(4):e0124934. Epub 2015/05/01. doi: 10.1371/journal.pone.0124934. PubMed PMID: 25928359; PubMed Central PMCID: PMCPMC4416030. 55. Knipe DW, Gunnell D, Pieris R, Priyadarshana C, Weerasinghe M, Pearson M, et al. Is socioeconomic position associated with risk of attempted suicide in rural Sri Lanka? A cross-sectional study of 165000 individuals. BMJ Open. 2017;7(3):e014006. Epub 2017/03/25. doi: 10.1136/bmjopen2016-014006. PubMed PMID: 28336743; PubMed Central PMCID: PMCPMC5372106.

56. Knipe DW, Carroll R, Thomas KH, Pease A, Gunnell D, Metcalfe C. Association of socioeconomic position and suicide/attempted suicide in low and middle income countries in South and SouthEast Asia - a systematic review. BMC Public Health. 2015;15:1055. Epub 2015/10/17. doi: 10.1186/s12889-015-2301-5. PubMed PMID: 26472204; PubMed Central PMCID: PMCPMC4608117. 57. Herne MA, Bartholomew ML, Weahkee RL. Suicide mortality among American Indians and Alaska Natives, 1999-2009. Am J Public Health. 2014;104 Suppl 3:S336-42. Epub 2014/04/24. doi: 10.2105/AJPH.2014.301929. PubMed PMID: 24754665; PubMed Central PMCID: PMCPMC4035873. 58. Shiels MS, Chernyavskiy P, Anderson WF, Best AF, Haozous EA, Hartge P, et al. Trends in premature mortality in the USA by sex, race, and ethnicity from 1999 to 2014: an analysis of death certificate data. Lancet. 2017;389(10073):1043-54. Epub 2017/01/31. doi: 10.1016/S01406736(17)30187-3. PubMed PMID: 28131493; PubMed Central PMCID: PMCPMC5388357. 59. Jorm AF, Patten SB, Brugha TS, Mojtabai R. Has increased provision of treatment reduced the prevalence of common mental disorders? Review of the evidence from four countries. World Psychiatry. 2017;16(1):90-9. Epub 2017/01/28. doi: 10.1002/wps.20388. PubMed PMID: 28127925; PubMed Central PMCID: PMCPMC5269479.

60. Marrast L, Himmelstein DU, Woolhandler S. Racial and Ethnic Disparities in Mental Health Care for Children and Young Adults: A National Study. Int J Health Serv. 2016;46(4):810-24. Epub 2016/08/16. doi: 10.1177/0020731416662736. PubMed PMID: 27520100.

61. Stone DM, Holland KM, Bartholow B, Crosby AE, Davis S, Wilkins N. Preventing Suicide: A Technical Package of Policies, Programs, and Practices. Atlanta, GA: National Center for Injury Prevention and Control, Centers for Disease Control and Prevention; 2017. p. https://www.cdc.gov/violenceprevention/pdf/suicideTechnicalPackage.pdf.

62. Christensen H, Cuijpers P, Reynolds CF, 3rd. Changing the Direction of Suicide Prevention Research: A Necessity for True Population Impact. JAMA Psychiatry. 2016;73(5):435-6. Epub 2016/03/17. doi: 10.1001/jamapsychiatry.2016.0001. PubMed PMID: 26982348.

63. Andrilla CHA, Patterson DG, Garberson LA, Coulthard C, Larson EH. Geographic Variation in the Supply of Selected Behavioral Health Providers. Am J Prev Med. 2018;54(6S3):S199-S207. Epub 2018/05/22. doi: 10.1016/j.amepre.2018.01.004. PubMed PMID: 29779543.

64. Bastiampillai T, Sharfstein SS, Allison S. Increase in US Suicide Rates and the Critical Decline in Psychiatric Beds. JAMA. 2016;316(24):2591-2. Epub 2016/11/05. doi: 10.1001/jama.2016.16989.

PubMed PMID: 27812693. 
65. Allison S, Bastiampillai T, Licinio J, Fuller DA, Bidargaddi N, Sharfstein SS. When should governments increase the supply of psychiatric beds? Mol Psychiatry. 2018;23(4):796-800. Epub 2017/07/12. doi: 10.1038/mp.2017.139. PubMed PMID: 28696434.

66. While D, Bickley H, Roscoe A, Windfuhr K, Rahman S, Shaw J, et al. Implementation of mental health service recommendations in England and Wales and suicide rates, 1997-2006: a cross-sectional and before-and-after observational study. Lancet. 2012;379(9820):1005-12. Epub 2012/02/07. doi:

10.1016/S0140-6736(11)61712-1. PubMed PMID: 22305767.

67. Zalsman G, Hawton K, Wasserman D, van Heeringen K, Arensman E, Sarchiapone M, et al. Suicide prevention strategies revisited: 10-year systematic review. Lancet Psychiatry. 2016;3(7):646-59. Epub 2016/06/13. doi: 10.1016/S2215-0366(16)30030-X. PubMed PMID: 27289303.

68. Relling MV, Evans WE. Pharmacogenomics in the clinic. Nature. 2015;526(7573):343-50. Epub 2015/10/16. doi: 10.1038/nature15817. PubMed PMID: 26469045; PubMed Central PMCID: PMCPMC4711261.

69. Licinio J, Wong ML. Pharmacogenomics of antidepressant treatment effects. Dialogues Clin Neurosci. 2011;13(1):63-71. Epub 2011/04/14. PubMed PMID: 21485747; PubMed Central PMCID: PMCPMC3181965.

70. Hamilton SP. The promise of psychiatric pharmacogenomics. Biol Psychiatry. 2015;77(1):29-35. Epub 2014/12/09. doi: 10.1016/j.biopsych.2014.09.009. PubMed PMID: 25483343.

71. Licinio J, Wong ML. Pharmacogenomics of antidepressants: what is next? Mol Psychiatry. 2010;15(5):445. Epub 2010/04/29. doi: 10.1038/mp.2010.58. PubMed PMID: 20424621.

72. Wong ML, Dong C, Flores DL, Ehrhart-Bornstein M, Bornstein S, Arcos-Burgos M, et al. Clinical outcomes and genome-wide association for a brain methylation site in an antidepressant pharmacogenetics study in Mexican Americans. Am J Psychiatry. 2014;171(12):1297-309. Epub 2014/09/16. doi: 10.1176/appi.ajp.2014.12091165. PubMed PMID: 25220861; PubMed Central PMCID: PMCPMC5746054.

73. Oquendo MA, Sullivan GM, Sudol K, Baca-Garcia E, Stanley BH, Sublette ME, et al. Toward a biosignature for suicide. Am J Psychiatry. 2014;171(12):1259-77. Epub 2014/09/30. doi: 10.1176/appi.ajp.2014.14020194. PubMed PMID: 25263730; PubMed Central PMCID: PMCPMC4356635.

74. Niculescu AB, Le-Niculescu H, Levey DF, Phalen PL, Dainton HL, Roseberry K, et al. Precision medicine for suicidality: from universality to subtypes and personalization. Mol Psychiatry.

2017;22(9):1250-73. Epub 2017/08/16. doi: 10.1038/mp.2017.128. PubMed PMID: 28809398; PubMed Central PMCID: PMCPMC5582166.

75. Duman RS. Ketamine and rapid-acting antidepressants: a new era in the battle against depression and suicide. F1000Res. 2018;7. Epub 2018/06/15. doi: 10.12688/f1000research.14344.1. PubMed PMID: 29899972; PubMed Central PMCID: PMCPMC5968361.

76. Wilkinson ST, Sanacora G. Considerations on the Off-label Use of Ketamine as a Treatment for Mood Disorders. JAMA. 2017;318(9):793-4. Epub 2017/08/15. doi: 10.1001/jama.2017.10697. PubMed PMID: 28806440.

77. Zanos P, Gould TD. Mechanisms of ketamine action as an antidepressant. Mol Psychiatry. 2018;23(4):801-11. Epub 2018/03/14. doi: 10.1038/mp.2017.255. PubMed PMID: 29532791; PubMed Central PMCID: PMCPMC5999402.

78. Abdallah CG, Sanacora G, Duman RS, Krystal JH. Ketamine and rapid-acting antidepressants: a window into a new neurobiology for mood disorder therapeutics. Annu Rev Med. 2015;66:509-23. Epub 2014/10/24. doi: 10.1146/annurev-med-053013-062946. PubMed PMID: 25341010; PubMed Central PMCID: PMCPMC4428310.

79. Zanos P, Moaddel R, Morris PJ, Riggs LM, Highland JN, Georgiou P, et al. Ketamine and Ketamine Metabolite Pharmacology: Insights into Therapeutic Mechanisms. Pharmacol Rev. 2018;70(3):621-60. Epub 2018/06/28. doi: 10.1124/pr.117.015198. PubMed PMID: 29945898; PubMed Central PMCID: PMCPMC6020109. 
80. Caley CF, Perriello E, Golden J. Antiepileptic drugs and suicide-related outcomes in bipolar disorder: A descriptive review of published data. Ment Health Clin. 2018;8(3):138-47. Epub 2018/06/30. doi: 10.9740/mhc.2018.05.138. PubMed PMID: 29955559; PubMed Central PMCID: PMCPMC6007633. 81. Brenner E. The Crisis of Youth Mental Health. In: Stanford Social Innovation Review, Spring 2019. https://ssir.org/articles/entry/the crisis_of youth_mental_health.

82. $\quad$ https://webappa.cdc.gov/sasweb/ncipc/leadcause.html.

83. https://www.healthypeople.gov/2020/about/foundation-health-measures/Disparities.

84. Kellermann AL, Rivara FP, Somes G, Reay DT, Francisco J, Banton JG, et al. Suicide in the home in relation to gun ownership. N Engl J Med. 1992;327(7):467-72. Epub 1992/08/13. doi: 10.1056/NEJM199208133270705. PubMed PMID: 1308093.

85. Wiebe DJ. Homicide and suicide risks associated with firearms in the home: a national casecontrol study. Ann Emerg Med. 2003;41(6):771-82. Epub 2003/05/24. doi: 10.1067/mem.2003.187. PubMed PMID: 12764330.

86. Anglemyer A, Horvath T, Rutherford G. The accessibility of firearms and risk for suicide and homicide victimization among household members: a systematic review and meta-analysis. Ann Intern Med. 2014;160(2):101-10. Epub 2014/03/05. doi: 10.7326/M13-1301. PubMed PMID: 24592495.

87. Miller M, Barber C, Azrael D, Hemenway D, Molnar BE. Recent psychopathology, suicidal thoughts and suicide attempts in households with and without firearms: findings from the National Comorbidity Study Replication. Inj Prev. 2009;15(3):183-7. Epub 2009/06/06. doi:

10.1136/ip.2008.021352. PubMed PMID: 19494098.

88. Miller M, Barber C, White RA, Azrael D. Firearms and suicide in the United States: is risk independent of underlying suicidal behavior? Am J Epidemiol. 2013;178(6):946-55. Epub 2013/08/27. doi: 10.1093/aje/kwt197. PubMed PMID: 23975641.

89. Miller M, Lippmann SJ, Azrael D, Hemenway D. Household firearm ownership and rates of suicide across the 50 United States. J Trauma. 2007;62(4):1029-34; discussion 34-5. Epub 2007/04/12. doi: 10.1097/01.ta.0000198214.24056.40. PubMed PMID: 17426563.

90. Kposowa A, Hamilton D, Wang K. Impact of Firearm Availability and Gun Regulation on State Suicide Rates. Suicide Life Threat Behav. 2016;46(6):678-96. Epub 2016/03/22. doi: 10.1111/sltb.12243. PubMed PMID: 26999372.

91. Mann JJ, Michel CA. Prevention of Firearm Suicide in the United States: What Works and What Is Possible. Am J Psychiatry. 2016;173(10):969-79. Epub 2016/07/23. doi:

10.1176/appi.ajp.2016.16010069. PubMed PMID: 27444796.

92. Opoliner A, Azrael D, Barber C, Fitzmaurice G, Miller M. Explaining geographic patterns of suicide in the US: the role of firearms and antidepressants. Inj Epidemiol. 2014;1(1):6. Epub 2014/12/01. doi: 10.1186/2197-1714-1-6. PubMed PMID: 27747669; PubMed Central PMCID: PMCPMC5005708. 93. Miller M, Hemenway D. Guns and suicide in the United States. N Engl J Med. 2008;359(10):989-91. Epub 2008/09/05. doi: 10.1056/NEJMp0805923. PubMed PMID: 18768940. 94. Simon OR, Swann AC, Powell KE, Potter LB, Kresnow MJ, O'Carroll PW. Characteristics of impulsive suicide attempts and attempters. Suicide Life Threat Behav. 2001;32(1 Suppl):49-59. Epub 2002/04/02. PubMed PMID: 11924695.

95. Lewiecki EM, Miller SA. Suicide, guns, and public policy. Am J Public Health. 2013;103(1):2731. Epub 2012/11/17. doi: 10.2105/AJPH.2012.300964. PubMed PMID: 23153127; PubMed Central PMCID: PMCPMC3518361.

96. https://gun-control.procon.org/view.resource.php?resourceID=006094.

97. Kalesan B, Villarreal MD, Keyes KM, Galea S. Gun ownership and social gun culture. Inj Prev. 2016;22(3):216-20. Epub 2015/07/01. doi: 10.1136/injuryprev-2015-041586. PubMed PMID: 26124073; PubMed Central PMCID: PMCPMC4809774.

98. Riddell CA, Harper S, Cerda M, Kaufman JS. Comparison of Rates of Firearm and Nonfirearm Homicide and Suicide in Black and White Non-Hispanic Men, by U.S. State. Ann Intern Med. 2018;168(10):712-20. https://www.mcgill.ca/newsroom/channels/news/suicide-and-homicide-rates-show- 
large-racial-disparities-across-us-states-286782. Epub 2018/05/02. doi: 10.7326/M17-2976. PubMed PMID: 29710093.

99. Pew Research Center. America's Complex Relationship With Guns. June 2017.

100. https://fivethirtyeight.blogs.nytimes.com/2012/12/18/in-gun-ownership-statistics-partisan-divideis-sharp/.

101. Chamard S. Correlates of Gun Ownership in Anchorage and the Mat-Su Borough. Alaska Justice Forum. 27(2)(Summer 2010):2-4.

102. Grinshteyn E, Hemenway D. Violent Death Rates: The US Compared with Other High-income OECD Countries, 2010. Am J Med. 2016;129(3):266-73. Epub 2015/11/10. doi:

10.1016/j.amjmed.2015.10.025. PubMed PMID: 26551975.

103. http://www.vpc.org/press/states-with-weak-gun-laws-and-higher-gun-ownership-lead-nation-ingun-suicides/.

104. Fleegler EW, Lee LK, Monuteaux MC, Hemenway D, Mannix R. Firearm legislation and firearm-related fatalities in the United States. JAMA Intern Med. 2013;173(9):732-40. Epub 2013/03/08. doi: 10.1001/jamainternmed.2013.1286. PubMed PMID: 23467753.

105. Kposowa AJ. Association of suicide rates, gun ownership, conservatism and individual suicide risk. Soc Psychiatry Psychiatr Epidemiol. 2013;48(9):1467-79. Epub 2013/03/05. doi: 10.1007/s00127013-0664-4. PubMed PMID: 23456258.

106. Kaufman EJ, Morrison CN, Branas CC, Wiebe DJ. State Firearm Laws and Interstate Firearm Deaths From Homicide and Suicide in the United States: A Cross-sectional Analysis of Data by County. JAMA Intern Med. 2018;178(5):692-700. Epub 2018/03/07. doi: 10.1001/jamainternmed.2018.0190. PubMed PMID: 29507953; PubMed Central PMCID: PMCPMC5885268.

107. Geier DA, Kern JK, Geier MR. A longitudinal ecological study of household firearm ownership and firearm-related deaths in the United States from 1999 through 2014: A specific focus on gender, race, and geographic variables. Prev Med Rep. 2017;6:329-35. Epub 2017/04/30. doi:

10.1016/j.pmedr.2017.04.004. PubMed PMID: 28451519; PubMed Central PMCID: PMCPMC5403795. 108. Ringgenberg W, Peek-Asa C, Donham K, Ramirez M. Trends and Characteristics of Occupational Suicide and Homicide in Farmers and Agriculture Workers, 1992-2010. J Rural Health. 2018;34(3):246-53. Epub 2017/05/04. doi: 10.1111/jrh.12245. PubMed PMID: 28464402.

109. https://www.washingtonpost.com/nation/2019/11/09/im-gonna-lose-everything/?arc404=true. 110. Curtin SC, Warner M, Hedegaard H. Increase in Suicide in the United States, 1999-2014. NCHS Data Brief. 2016;(241):1-8. Epub 2016/04/26. PubMed PMID: 27111185.

111. Miller M, Azrael D, Hepburn L, Hemenway D, Lippmann SJ. The association between changes in household firearm ownership and rates of suicide in the United States, 1981-2002. Inj Prev.

2006;12(3):178-82. Epub 2006/06/06. doi: 10.1136/ip.2005.010850. PubMed PMID: 16751449; PubMed Central PMCID: PMCPMC2563517.

112. Anestis MD, Anestis JC. Suicide Rates and State Laws Regulating Access and Exposure to Handguns. Am J Public Health. 2015;105(10):2049-58. Epub 2015/08/14. doi:

10.2105/AJPH.2015.302753. PubMed PMID: 26270305; PubMed Central PMCID: PMCPMC4566524. 113. Luca M, Malhotra D, Poliquin C. Handgun waiting periods reduce gun deaths. Proc Natl Acad Sci U S A. 2017;114(46):12162-5. Epub 2017/10/29. doi: 10.1073/pnas.1619896114. PubMed PMID: 29078268; PubMed Central PMCID: PMCPMC5699026.

114. Crifasi CK, Meyers JS, Vernick JS, Webster DW. Effects of changes in permit-to-purchase handgun laws in Connecticut and Missouri on suicide rates. Prev Med. 2015;79:43-9. Epub 2015/07/28. doi: 10.1016/j.ypmed.2015.07.013. PubMed PMID: 26212633.

115. Grossman DC, Mueller BA, Riedy C, Dowd MD, Villaveces A, Prodzinski J, et al. Gun storage practices and risk of youth suicide and unintentional firearm injuries. JAMA. 2005;293(6):707-14. Epub 2005/02/11. doi: 10.1001/jama.293.6.707. PubMed PMID: 15701912.

116. Sarai SK, Abaid B, Lippmann S. Guns and Suicide: Are They Related? Prim Care Companion CNS Disord. 2017;19(6). Epub 2017/12/23. doi: 10.4088/PCC.17br02116. PubMed PMID: 29272571. 
117. Appelbaum PS, Swanson JW. Law \& psychiatry: Gun laws and mental illness: how sensible are the current restrictions? Psychiatr Serv. 2010;61(7):652-4. Epub 2010/07/02. doi:

10.1176/ps.2010.61.7.652. PubMed PMID: 20591996.

118. Webster DW, Vernick JS, Zeoli AM, Manganello JA. Association between youth-focused firearm laws and youth suicides. JAMA. 2004;292(5):594-601. Epub 2004/08/05. doi: 10.1001/jama.292.5.594.

PubMed PMID: 15292085.

119. Cummings P, Grossman DC, Rivara FP, Koepsell TD. State gun safe storage laws and child mortality due to firearms. JAMA. 1997;278(13):1084-6. Epub 1997/10/07. PubMed PMID: 9315767.

120. Gius M. The impact of minimum age and child access prevention laws on firearm-related youth suicides and unintentional deaths. The Social Science Journal. 2015;52(2):168-75.

121. Parker K, Horowitz J, Igielnik R, Oliphant B, Brown A. America's complex relationship with guns: An in-depth look at the attitudes and experiences of US adults: Pew Research Center, ; 2017.

122. Butterworth SE, Anestis MD. Political beliefs, region of residence, and openness to firearm means safety measures to prevent suicide. Arch Suicide Res. 2018:1-32. Epub 2018/06/29. doi:

10.1080/13811118.2018.1486250. PubMed PMID: 29952717.

123. McCourt AD, Vernick JS, Betz ME, Brandspigel S, Runyan CW. Temporary Transfer of Firearms From the Home to Prevent Suicide: Legal Obstacles and Recommendations. JAMA Intern Med. 2017;177(1):96-101. Epub 2016/11/15. doi: 10.1001/jamainternmed.2016.5704. PubMed PMID: 27842186.

124. Vernick JS, Alcorn T, Horwitz J. Background Checks for all Gun Buyers and Gun Violence Restraining Orders: State Efforts to Keep Guns from High-Risk Persons. J Law Med Ethics. 2017;45(1_suppl):98-102. Epub 2017/07/01. doi: 10.1177/1073110517703344. PubMed PMID: 28661309.

125. Kivisto AJ, Phalen PL. Effects of Risk-Based Firearm Seizure Laws in Connecticut and Indiana on Suicide Rates, 1981-2015. Psychiatr Serv. 2018:appips201700250. Epub 2018/06/02. doi: 10.1176/appi.ps.201700250. PubMed PMID: 29852823.

126. Betz ME, Wintemute GJ. Physician Counseling on Firearm Safety: A New Kind of Cultural Competence. JAMA. 2015;314(5):449-50. Epub 2015/08/05. doi: 10.1001/jama.2015.7055. PubMed PMID: 26241594; PubMed Central PMCID: PMCPMC4559221.

127. Runyan CW, Becker A, Brandspigel S, Barber C, Trudeau A, Novins D. Lethal Means Counseling for Parents of Youth Seeking Emergency Care for Suicidality. West J Emerg Med. 2016;17(1):8-14. Epub 2016/01/30. doi: 10.5811/westjem.2015.11.28590. PubMed PMID: 26823923; PubMed Central PMCID: PMCPMC4729425.

128. Vriniotis M, Barber C, Frank E, Demicco R, New Hampshire Firearm Safety C. A suicide prevention campaign for firearm dealers in New Hampshire. Suicide Life Threat Behav. 2015;45(2):15763. Epub 2014/10/29. doi: 10.1111/sltb.12123. PubMed PMID: 25348506.

129. https://www.hsph.harvard.edu/means-matter/gun-shop-project/.

130. Swanson JW, Norko MA, Lin H-J, Alanis-Hirsch K, Frisman LK, Baranoski MV, et al. Implementation and Effectiveness of Connecticut's Risk-Based Gun Removal Law: Does It Prevent Suicides. Law \& Contemp Probs. 2017;80:179.

131. Rodriguez Andres A, Hempstead K. Gun control and suicide: the impact of state firearm regulations in the United States, 1995-2004. Health Policy. 2011;101(1):95-103. Epub 2010/11/04. doi: 10.1016/j.healthpol.2010.10.005. PubMed PMID: 21044804.

132. https://Www.gpo.gov/fdsys/pkg/PLAW-104publ208/pdf/PLAW-104publ208.pdf.

133. Jamieson C. Gun violence research: History of the federal funding freeze. Psychological Science Agenda, February 2013.

134. Hemenway D. Fight the silencing of gun research. Nature. 2017;546(7658):345-7. Epub 2017/06/16. doi: 10.1038/546345a. PubMed PMID: 28617476.

135. Wadman M. Firearms research: The gun fighter. Nature. 2013;496(7446):412-5. Epub 2013/04/27. doi: 10.1038/496412a. PubMed PMID: 23619673. 
136. Rubin R. Tale of 2 Agencies: CDC Avoids Gun Violence Research But NIH Funds It. JAMA. 2016;315(16):1689-91. Epub 2016/04/07. doi: 10.1001/jama.2016.1707. PubMed PMID: 27050067.

137. Caswell W. Gun Violence reframed as a Public Health issue. Modern Health Talk, 03/05/2018. http://www.mhealthtalk.com/guns/.

138. Stark DE, Shah NH. Funding and Publication of Research on Gun Violence and Other Leading Causes of Death. JAMA. 2017;317(1):84-5. Epub 2016/12/29. doi: 10.1001/jama.2016.16215. PubMed PMID: 28030692.

139. Kristof N. How to Reduce Shootings. New York Times, May 18, 2018.

https://www.nytimes.com/interactive/2017/11/06/opinion/how-to-reduce-shootings.html.

140. The Truth About Suicide \& Guns. Brady Campaign to Prevent Gun Violence.

2016; http://www.bradycampaign.org/sites/default/files/Brady-Guns-Suicide-Report-2016.pdf.

141. Americans Overwhelmingly See Gun Violence as a Public Health Issue; They Want Congress to Act and CDC to Conduct Research. American Psychiatric Association (APA) Public Opinion Poll, May 07, 2018. https://www.psychiatry.org/newsroom/news-releases/americans-overwhelmingly-see-gun-

violence-as-a-public-health-issue-they-want-congress-to-act-and-cdc-to-conduct-research.

142. https://www.jec.senate.gov/public/ cache/files/15702336-e9b5-4258-bf3d-

c53b407cf550/jec2019-gunsandsuicide-final.pdf. 